ARTICLE

Received 17 Nov 2015 | Accepted 20 May 2016 | Published 5 Jul 2016

DOI: $10.1038 /$ ncomms11997

OPEN

\title{
A spliceosome intermediate with loosely associated tri-snRNP accumulates in the absence of Prp28 ATPase activity
}

\author{
Carsten Boesler ${ }^{1, \dagger}$, Norbert Rigo ${ }^{1}$, Maria M. Anokhina', Marcel J. Tauchert ${ }^{2}$, Dmitry E. Agafonov ${ }^{1}$, \\ Berthold Kastner ${ }^{1}$, Henning Urlaub ${ }^{3,4}$, Ralf Ficner ${ }^{2}$, Cindy L. Will ${ }^{1} \&$ Reinhard Lührmann ${ }^{1}$
}

The precise role of the spliceosomal DEAD-box protein Prp28 in higher eukaryotes remains unclear. We show that stable tri-snRNP association during pre-catalytic spliceosomal B complex formation is blocked by a dominant-negative hPrp28 mutant lacking ATPase activity. Complexes formed in the presence of ATPase-deficient hPrp28 represent a novel assembly intermediate, the pre-B complex, that contains U1, U2 and loosely associated tri-snRNP and is stalled before disruption of the U1/5'ss base pairing interaction, consistent with a role for hPrp28 in the latter. Pre-B and B complexes differ structurally, indicating that stable tri-snRNP integration is accompanied by substantial rearrangements in the spliceosome. Disruption of the U1/5'ss interaction alone is not sufficient to bypass the block by ATPase-deficient hPrp28, suggesting hPrp28 has an additional function at this stage of splicing. Our data provide new insights into the function of Prp28 in higher eukaryotes, and the requirements for stable tri-snRNP binding during B complex formation.

\footnotetext{
${ }^{1}$ Department of Cellular Biochemistry, MPI for Biophysical Chemistry, Am Fassberg 11, D-37077 Göttingen, Germany. ${ }^{2}$ Department of Molecular Structura Biology, Institute for Microbiology and Genetics, GZMB, Georg-August-Universität Göttingen, Justus-von-Liebig-Weg 11, D-37077 Göttingen, Germany. ${ }^{3}$ Bioanalytical Mass Spectrometry Group, MPI for Biophysical Chemistry, Am Fassberg 11, D-37077 Göttingen, Germany. ${ }^{4}$ Bioanalytics Group, Institute for Clinical Chemistry, University Medical Center Göttingen, Robert-Koch-Straße 40, D-37075 Göttingen, Germany. †Present address: Targos Molecular Pathology GmbH, Germaniastrasse 7, D-34119 Kassel, Germany. Correspondence and requests for materials should be addressed to

C.L.W. (email: cwill1@gwdg.de) or to R.L. (email: reinhard.luehrmann@mpi-bpc.mpg.de).
} 
$\mathrm{T}$ he spliceosome is a highly dynamic molecular machine that assembles de novo for each round of splicing by the ordered interaction of five small nuclear ribonucleoproteins (snRNPs) and numerous splicing factors with the premRNA $^{1}$. Initial spliceosome assembly can occur across an exon if the adjacent intron is longer than $\sim 250 \mathrm{nt}$. In this case, U2 snRNP binds the branch point sequence (BPS) upstream of the exon and U1 snRNP interacts with the $5^{\prime}$ splice site (ss) downstream of it, forming a cross-exon complex ${ }^{2}$. In contrast, stepwise assembly of the spliceosome across an intron is initiated by interaction of U1 snRNP with the $5^{\prime}$ ss and U2 snRNP with the downstream BPS of the intron, yielding the spliceosomal A complex. Stable U4/U6.U5 tri-snRNP binding then generates the pre-catalytic B complex. Subsequently, the $\mathrm{B}^{\text {act }}$ and then $\mathrm{B}^{*}$ complex, which catalyses step I of splicing, are generated. $B^{*}$ is transformed into complex $\mathrm{C}$, which contains the cleaved $5^{\prime}$ exon and the intron-lariat- $3^{\prime}$ exon splicing intermediates. Complex C then catalyses step II of splicing, during which the lariat intron is excised and the $5^{\prime}$ and $3^{\prime}$ exons are ligated.

The spliceosome undergoes multiple structural and compositional rearrangements, including extensive changes in its RNA-RNA network ${ }^{3,4}$. In complex A, the U1 and U2 snRNAs base pair with the $5^{\prime}$ ss and BPS, respectively. The U4/U6.U5 tri-snRNP, in which the U4 and U6 snRNAs are extensively base paired, associates with complex $\mathrm{A}$, and a short helix between the $3^{\prime}$ end of U6 and 5'end of U2 (U2/U6 helix II) is formed. Subsequently, the U1/5'ss interaction is disrupted, allowing base pairing of the $5^{\prime}$ ss with the conserved ACAGA box of U6 snRNA. On unwinding of the U4/U6 duplex, U6 forms a functionally important intramolecular stem-loop and interacts with U2 to form U2/U6 helix I, generating the spliceosome's catalytically active RNA network ${ }^{5}$.

Structural rearrangements in the spliceosome are driven by eight conserved DExD/H-box ATPases/helicases ${ }^{6,7}$ that couple the energy of ATP hydrolysis to structural and/or compositional rearrangements at distinct steps of the splicing cycle ${ }^{8,9}$. One of these essential factors is the DEAD-box protein Prp28, an integral component of the U5 snRNP and U4/U6.U5 tri-snRNP ${ }^{10}$ in human, but not in Saccharomyces cerevisiae $(S \text {. cerevisiae })^{11}$. Prp28 contains all eight conserved motifs (I-VIII) present in DEAD-box proteins that are required for ATPase and RNA unwinding activity ${ }^{10}$. In yeast, mutation of these motifs indicated that Prp28's putative ATPase and helicase activities are required for pre-mRNA splicing in vivo ${ }^{12}$. However, isolated Prp28 exhibits very little ${ }^{13}$ or no ${ }^{11,14-16}$ ATPase activity in vitro, and to date no RNA unwinding activity could be demonstrated. Indeed, isolated yeast and human (h)Prp28 adopt a conformation not conducive for ATP hydrolysis, with their RecA domains in an open conformation $^{13,16}$. In human, hPrp28 first binds ATP after incorporation into the spliceosome, suggesting that interactions with other spliceosome components lead to a structural change in hPrp28 that enables ATP binding and potentially triggers its ATPase activity ${ }^{16}$.

In S. cerevisiae, Prp28 plays an essential role in destabilizing the U1/5'ss duplex, thereby allowing the exchange of U1 for U6 snRNA interaction with the $5^{\prime}$ ss (refs 17,18). Mutations in yeast U1 snRNP proteins that destabilize the U1/5'ss interaction can bypass the need for Prp28 (refs 18,19). In human, immunodepletion of hPrp28 from HeLa nuclear extract blocks the $\mathrm{A}$ to $\mathrm{B}$ complex transition ${ }^{20}$. In addition, phosphorylation of hPrp28 by serine-arginine protein kinase 2 is necessary for hPrp28 integration into the U4/U6.U5 tri-snRNP and only tri-snRNPs containing hPrp28 are competent for stable B complex formation ${ }^{20}$. However, the precise role of Prp28 in higher eukaryotes, including whether its enzymatic activity is required for stable B complex formation, remains unclear.
Stable U4/U6.U5 tri-snRNP integration during human B complex formation not only depends on the presence of hPrp28, but also is aided by other spliceosomal proteins including serinearginine rich (SR) proteins ${ }^{21}$, the tri-snRNP proteins hSAD1 and hSART1 (ref. 22), and SPF30 (refs 23,24). During B complex formation, B-specific proteins interact with the spliceosome but are released already during the subsequent activation stage ${ }^{25,26}$. These proteins thus potentially aid in stable tri-snRNP integration during B complex formation ${ }^{25,27}$. Several tri-snRNP components, including the U5 and U6 snRNAs ${ }^{28,29}$ and the proteins Prp8 and Prp28 (refs 30,31), interact with the $5^{\prime}$ ss in mammalian B complexes, and thus likely also contribute to stable tri-snRNP binding.

Here we dissect the role of $h \operatorname{Prp} 28$ in mammalian splicing in vitro and identify a novel intermediate of the cross-intron spliceosome assembly pathway, namely the $37 \mathrm{~S}$ pre-B complex. Our data provide new insights into Prp28's function during splicing, and also into the initial recruitment and subsequent stable integration of the tri-snRNP during assembly of the pre-catalytic spliceosome.

\section{Results}

A hPrp28 mutant stalls spliceosome assembly before complex $B$. To dissect the role of the DEAD-box protein hPrp28 during human spliceosomal B complex formation, we first assayed the effect of an excess of hPrp28, in which the DEAD motif was mutated to AAAD (designated hPrp28 ${ }^{\mathrm{AAAD}}$ ), on MINX-MS2 pre-mRNA splicing in vitro. As amino acids from the DEAD-box motif are involved in ATP hydrolysis ${ }^{32,33}$, these mutations should abolish Prp28's ATPase activity. Because hPrp28 adopts an active conformation first when incorporated into the spliceosome ${ }^{16}$, the ATPase activity of recombinant $\mathrm{hPr} 22^{\mathrm{AAAD}}$ could not be tested in vitro. However, a single alanine mutation in the DEAD motif (DEAD to AEAD) of yeast Prp28 severely reduced its ATPase activity, and yPrp2 $28^{\mathrm{AEAD}}$, as well as $y \operatorname{Prp} 28^{\mathrm{DAAD}}$, exhibit a lethal phenotype in vivo ${ }^{13}$. Addition of hPrp28AAAD, but not recombinant wild-type protein, impaired pre-mRNA splicing in vitro (Fig. 1a), with nearly complete inhibition of both catalytic steps observed at $50 \mathrm{ng}^{-1}{ }^{-1}$, which corresponds to a $\sim 50$-fold excess over the endogenous protein. Thus, hPrp28 ${ }^{\mathrm{AAAD}}$ acts as a dominant-negative mutant that inhibits splicing before the first catalytic step. This suggests that $\mathrm{hPrp} 28^{\mathrm{AAAD}}$ competes with the endogenous wild-type protein for binding but due to its inactivity, spliceosome assembly is blocked. To identify at which stage splicing is inhibited, spliceosomal complexes were assembled in the presence of a 50 -fold excess of $h \operatorname{Prp} 28^{\mathrm{AAAD}}$ and then analysed by native gel electrophoresis in the presence of heparin. Formation of $\mathrm{A}, \mathrm{B}$ and $\mathrm{C}$ complexes was observed in reactions lacking hPrp28 $\mathrm{AAAD}$ or containing wild-type recombinant hPrp28 (Fig. 1b). In contrast, in the presence of hPrp28 ${ }^{\mathrm{AAAD}}, \mathrm{B}$ complex assembly was severely reduced and A complexes accumulated (Fig. 1b). Thus, spliceosome assembly is stalled during the A to B complex transition, indicating that $h \operatorname{Prp} 28$ activity is required at this stage. In S. cerevisiae Prp28 also plays a very early role before U2 recruitment to the spliceosome ${ }^{34}$. However, the rate of stable U2 snRNP recruitment (that is, A complex formation) was not substantially altered in the presence of hPrp28 $8^{\text {AAAD }}$ (Supplementary Fig. 1).

Purification of a novel spliceosome assembly intermediate. To analyse the stalled spliceosomal complexes in more detail, we purified them by glycerol gradient centrifugation and subsequent MS2 affinity selection. Spliceosomes assembled in the presence of $\mathrm{hPrp} 28^{\mathrm{AAAD}}$ peaked in the $\sim 37 \mathrm{~S}$ region of the gradient, whereas B complexes formed after 6 min of splicing without hPrp $28^{A A A D}$ 
a

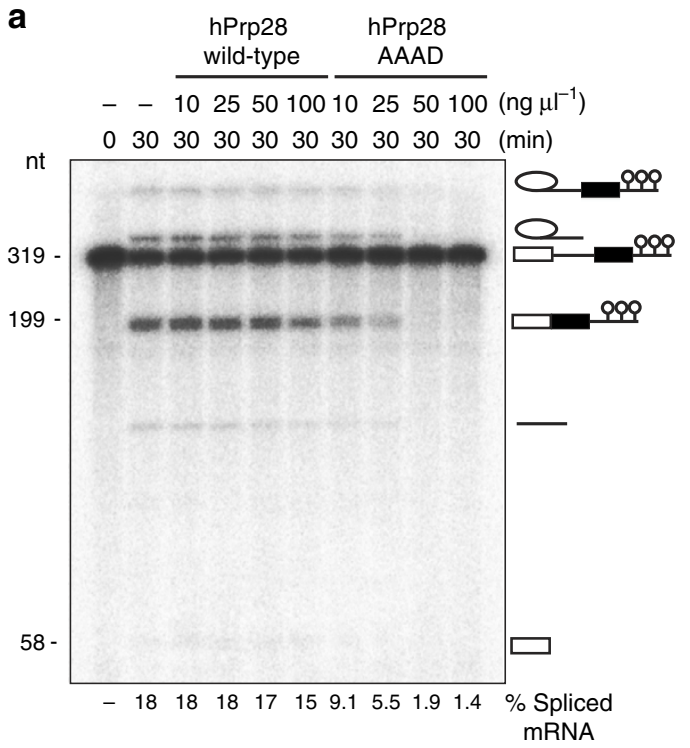

C

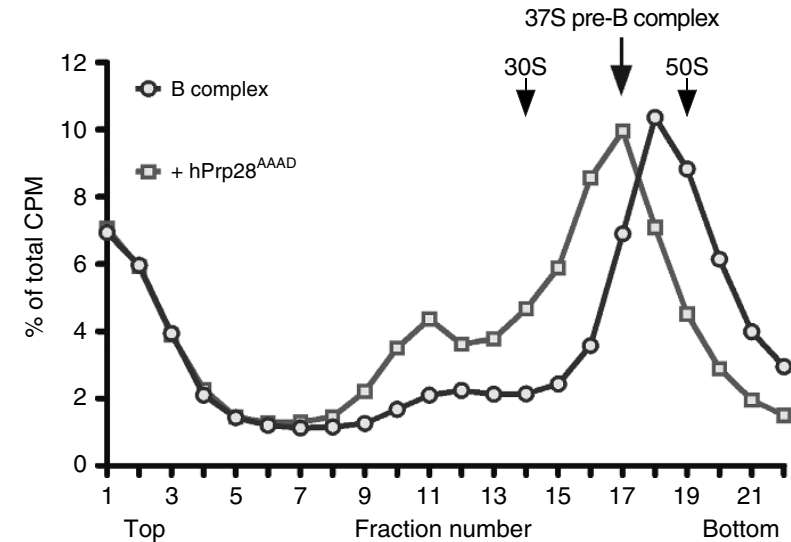

b

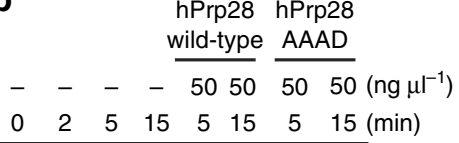

$\begin{array}{llllllll}0 & 2 & 5 & 15 & 5 & 15 & 5 & 15\end{array}$

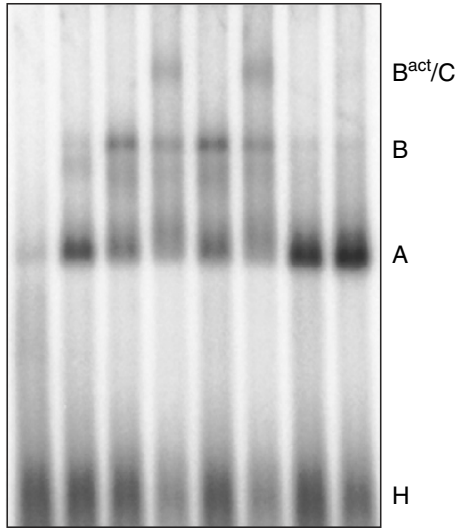

e

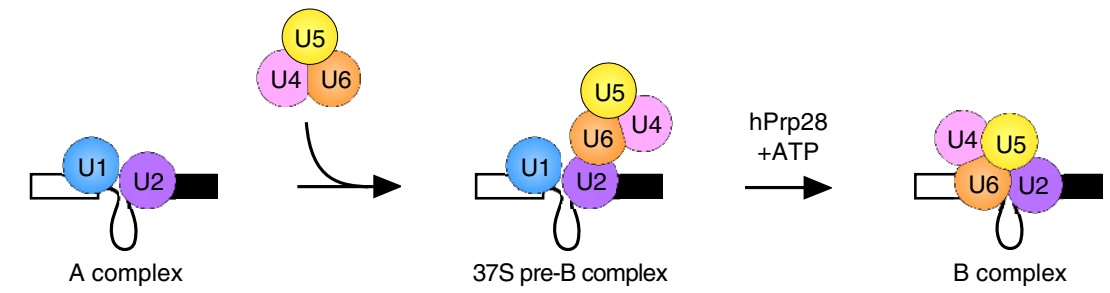

Figure 1 | An excess of ATPase-deficient hPrp28 stalls splicing before spliceosomal B complex formation. (a) In vitro splicing of 32 P-labelled MINX-MS2 pre-mRNA in HeLa nuclear extract in the presence of increasing amounts $\left(10-100 \mathrm{ng} \mathrm{\mu l}{ }^{-1}\right.$ ) of recombinant hPrp28 or an AAAD mutant (hPrp28 AAAD) thereof, as indicated above each lane. RNA was analysed by denaturing PAGE and visualized by autoradiography. The positions of the pre-mRNA, and splicing intermediates and products are indicated on the right. The nucleotide length of the pre-mRNA, mRNA and $5^{\prime}$ exon is indicated on the left. The \% spliced mRNA is indicated below each lane. The average \% spliced mRNA \pm s.d. (from three independent experiments) observed in the presence of 50 and $100 \mathrm{ng} \mathrm{\mu l}^{-1} \mathrm{hPrp} 28^{\mathrm{AAAD}}$ was $2.65 \pm 0.80$ and $2.05 \pm 0.77$, respectively. (b) Analysis of splicing complexes formed in nuclear extract in the presence of $50 \mathrm{ng} \mathrm{\mu l}^{-1} \mathrm{hPrp} 28$ or hPrp28 $\mathrm{AAAD}$ by agarose gel electrophoresis in the presence of heparin. The positions of $\mathrm{H}, \mathrm{A}, \mathrm{B}$ and $\mathrm{B}^{\text {act }} / \mathrm{C}$ complexes are indicated. (c) Splicing complexes were assembled on ${ }^{32}$ P-labelled MINX-MS2 pre-mRNA in HeLa nuclear extract for 6 min either in the absence or presence of an inhibitory concentration $\left(50 \mathrm{ng} \mathrm{\mu l}^{-1}\right)$ of the recombinant hPrp28 $8^{A A A D}$ protein, and were analysed on a 10-30\% glycerol gradient containing G-150 buffer. The percent of total radioactivity in each gradient fraction is plotted. Sedimentation values were determined using prokaryotic ribosomal subunits run in parallel. (d) Spliceosomal complexes in peak fractions (37S pre-B, fractions 16-18; B complex, fractions 17-19) were subjected to MS2 affinity selection and RNA was analysed by denaturing PAGE followed by silver staining. RNA identities are indicated on the right. Nucleotide length (nt) markers are derived from the snRNAs from purified human $37 \mathrm{~S}$ cross-exon complexes run in parallel. (e) Schematic of the spliceosome assembly stages leading to a precatalytic B complex.

peaked at $\sim 45 \mathrm{~S}$ (Fig. 1c). Affinity-purified $37 \mathrm{~S}$ spliceosomes formed in the presence of hPrp28 $8^{\mathrm{AAA}}$ contained stoichiometric amounts of all five snRNAs plus the MINX-MS2 pre-mRNA (Fig. 1d). In contrast, U1 snRNA was substantially underrepresented in purified B complexes (Fig. 1d). Thus, in the presence of hPrp28 $\mathrm{AAAD}$, stoichiometric amounts of U1 snRNP remain associated with the pre-mRNA, and the tri-snRNP is recruited but not yet stably bound, as evidenced by the absence of 


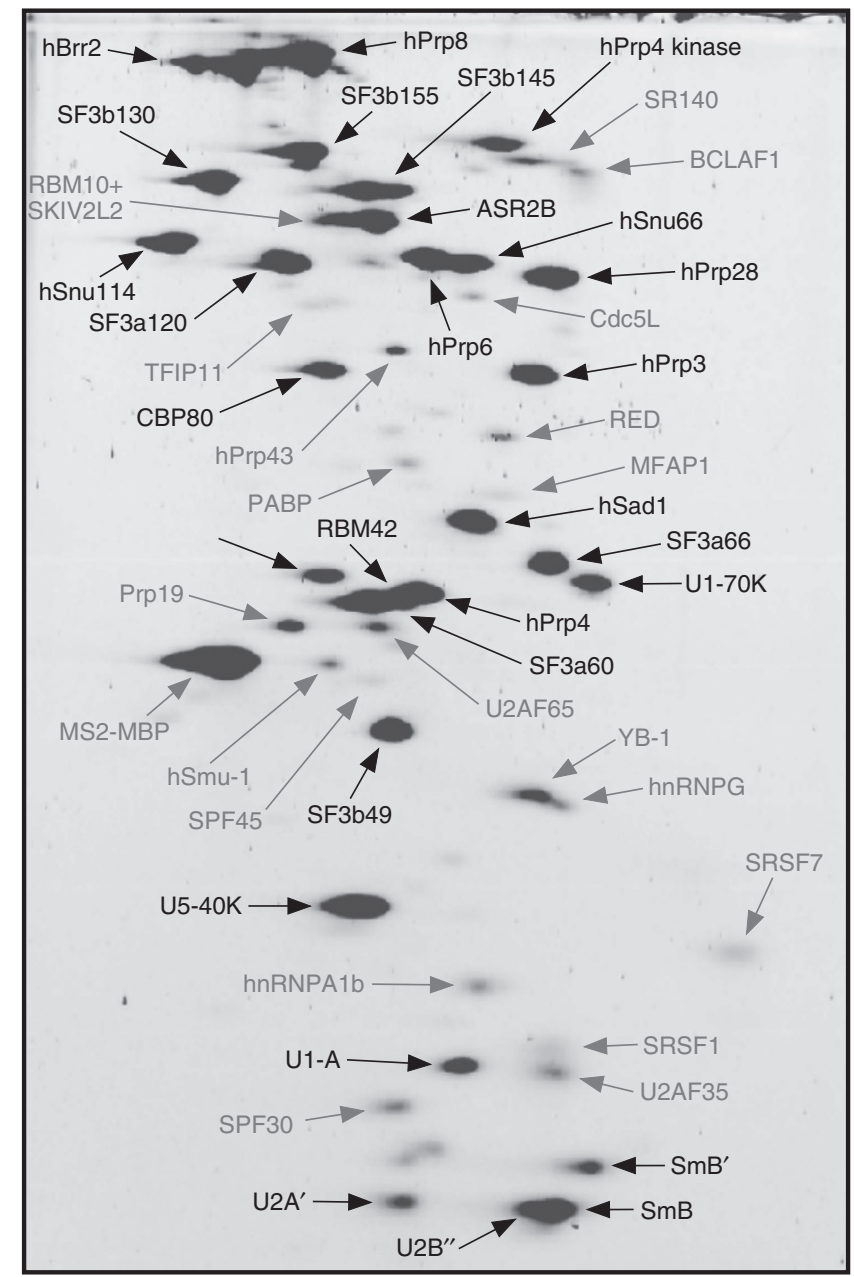

Figure 2 | Identification of abundant proteins in purified 37S pre-B

complexes. Proteins ( $>25 \mathrm{kDa}$ ) associated with affinity-purified $37 \mathrm{~S}$ pre-B complexes were separated by 2D gel electrophoresis, stained with RuBPS, and the identities of single protein spots were determined by mass spectrometry. Abundant proteins were identified by visual inspection and are indicated in black, and less abundant ones in grey.

a B complex in native gels in the presence of heparin (Fig. 1b). As a complex with these characteristics has not yet been described, it represents a novel mammalian spliceosome assembly intermediate (henceforth termed the $37 \mathrm{~S}$ pre-B complex), formed after complex A but before hPrp28 action and stable tri-snRNP integration (Fig. 1e).

Mass spectrometry (MS) of affinity-purified pre-B complexes revealed that, consistent with their snRNA composition, they contain nearly all proteins associated with the U1 and U2 snRNPs, and U4/U6.U5 tri-snRNP, including hPrp28 (Supplementary Data 1). Thus, the defect in spliceosome assembly is not due to the absence of hPrp28, but presumably its lack of enzymatic activity. Indeed, western blot analyses showed that endogenous hPrp28 was quantitatively replaced by the hPrp $28^{\mathrm{AAAD}}$ mutant in affinity-purified pre-B complexes (Supplementary Fig. 2), indicating that hPrp2 $28^{A A A D}$ outcompetes the endogenous protein for binding to the spliceosome. Compared with complex B, the pre-B complex contained lower peptide counts for the B-specific proteins RED, MFAP1, FBP21, hSmu-1, hPrp38 and hSnu23, and the Prp19/CDC5L complex and related proteins. To determine which proteins are present in stoichiometric amounts, we performed two-dimensional (2D) gel electrophoresis followed by MS. Abundant proteins (with a molecular mass above $25 \mathrm{kDa}$ ) in pre-B complexes included essentially all U1, U2 and U4/U6, U5 and tri-snRNP proteins plus hPrp4 kinase, CBP80 and ASR2B (Fig. 2, Table 1). The 2D analysis also confirmed that the B-specific proteins are present in very low levels. B complexes contain a similar set of abundant proteins, except that hPrp4 kinase, RBM42 and U1 snRNP proteins are no longer abundant, and most B-specific proteins, plus SRSF1, hnRNP A1 and hPrp19 are present in large amounts ${ }^{26}$. Thus, an excess of hPrp $28^{A A A D}$ blocks spliceosome assembly before U1 displacement and recruitment of B-specific proteins.

hPrp6 and hPrp31 are phosphorylated by hPrp4 kinase during $\mathrm{B}$ complex formation ${ }^{35}$. As hPrp4 kinase is abundant in pre-B complexes, we assayed via western blot whether hPrp31 is phosphorylated at this stage, using antibodies specific for phosphorylated hPrp31. Only a very low level of phosphohPrp31 was detected in purified pre-B complexes compared with B (Supplementary Fig. 2), indicating that hPrp4 kinase is activated during the pre-B to $\mathrm{B}$ transition.

Analysis of the RNA-RNA network in the $37 \mathrm{~S}$ pre-B complex. We next investigated RNA-RNA interactions within pre-B and $\mathrm{B}$ complexes by performing psoralen ( $4^{\prime}$-aminomethyl- $4,5^{\prime}, 8$-trimethylpsoralen, AMT) crosslinking. RNA-RNA crosslinks were analysed via Northern blotting by sequentially incubating with ${ }^{32} \mathrm{P}$-labelled probes against MINX pre-mRNA and the U1, U2, U4, U5 and U6 snRNAs. Several bands were detected by two or more probes, indicating crosslinking of two (or more) of these RNAs (Fig. 3a; Supplementary Fig. 3). For example, crosslinks between U2 and U6, and U4 and U6, and a triple crosslink between U2, U4 and U6 were observed in both complexes (Fig. 3a). The migration behaviour of the U2/U6 crosslink indicates formation of U2/U6 helix II (ref. 36), and thus the U4/U6.U5 tri-snRNP docks with the pre-B complex, at least in part, by interacting with U2.

Several slowly migrating bands were observed with the MINXMS2 pre-mRNA and the snRNAs (with the exception of U5) after ultraviolet irradiation, indicating the formation of pre-mRNA/ snRNA crosslinks. To confirm that these bands contained the pre-mRNA, we performed RNase $\mathrm{H}$ cleavage with a DNA oligonucleotide complementary to the $3^{\prime}$ exon of the MINX-MS2 pre-mRNA (designated exon oligo); loss or reduction in a given crosslinked species after $\mathrm{RNase} \mathrm{H}$ digestion indicates the presence of pre-mRNA. Two slower migrating bands were detected with both the pre-mRNA and U1 probes in the pre-B complex but only weakly in B (Fig. 3a, lanes 1-8 and 9-16). RNAse $\mathrm{H}$ digestion with the exon oligo reduced their intensity and led to the appearance of two faster migrating bands that are detected by the U1 and pre-mRNA probes (Fig. 3a). This demonstrates crosslink formation between the pre-mRNA and U1, consistent with a U1/5ss interaction in the pre-B complex, and thus the requirement for hPrp28 activity for U1/5'ss unwinding. Although U2 snRNA base pairs with the BPS already in complex $\mathrm{A}^{37}$, a premRNA/U2 crosslink was not observed with either complex, likely due to inaccessibility of the U2/BPS duplex to psoralen; indeed a U2/pre-mRNA crosslink was not observed previously with human $\mathrm{B}$ or $\mathrm{B}^{\text {act }}$ complexes ${ }^{36}$.

In contrast, several slowly migrating bands were observed with both the pre-mRNA and U6, U4 and U2 probes, with the B complex, but only very weakly or not at all with pre-B. These bands include pre-mRNA/U6/U4/U2, pre-mRNA/U6/U2, pre-mRNA/U6/U4 and pre-mRNA/U6 crosslinked species (Fig. 3). The latter likely co-migrates with the very strong $\mathrm{U} 2 / \mathrm{U} 4 / \mathrm{U} 6$ crosslink and is only visible after RNAse $\mathrm{H}$ digestion with the exon oligo (Fig. 3, lanes 46-48). Previous psoralen 


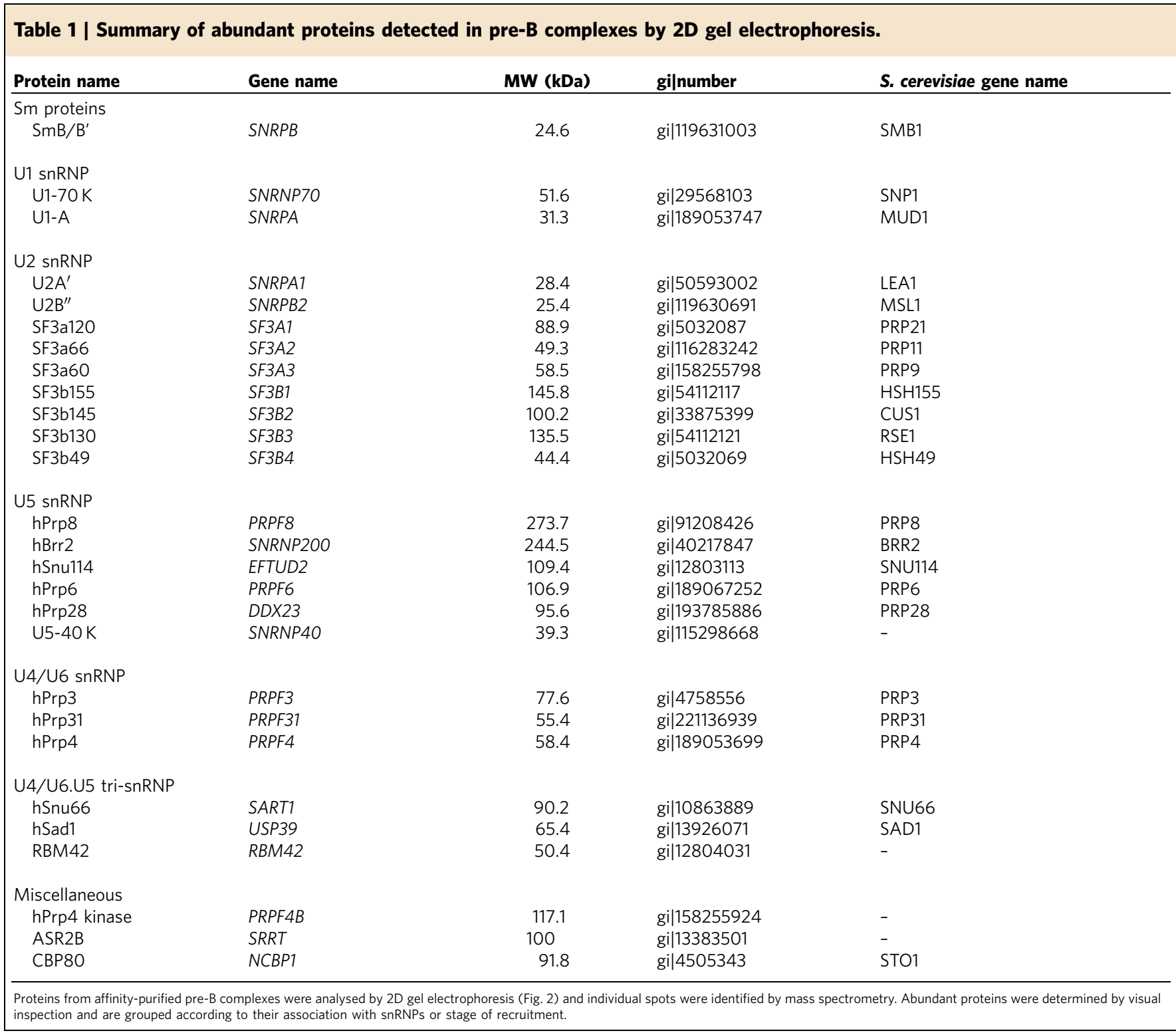

crosslinking studies analysing affinity-purified human B complexes formed on PM5 pre-mRNA, confirmed the formation of a U6/pre-mRNA crosslink that, due to the increased length of PM5 versus MINX pre-mRNA, no longer co-migrated with the U2/U4/ U6 triple crosslink and was thus visible even without RNAse $\mathrm{H}$ digestion $^{36}$. Formation of a U6/pre-mRNA crosslink (and other crosslinks containing U6, the pre-mRNA and additional snRNAs) is consistent with an interaction between the U6 ACAGA box and intron nucleotides near the $5^{\prime}$ ss. Thus, in the $37 \mathrm{~S}$ pre- $\mathrm{B}$ complex the U1 snRNP is still base paired at the $5^{\prime}$ ss, while the U4/U6.U5 tri-snRNP associates, at least partially, via U2/U6 helix II (Fig. 3b). In the B complex, U1 snRNA is displaced from the $5^{\prime}$ ss and U6 snRNA interacts with intron nucleotides near the $5^{\prime}$ ss.

Pre-B complexes can be chased into active spliceosomes. To determine whether the $\mathrm{hPrp} 28^{\mathrm{AAAD}}$-stalled pre-B complex is a functional assembly intermediate, we performed chase experiments. When affinity-purified pre-B complexes were incubated under splicing conditions in the absence of extract, or after addition of hPrp $28^{\mathrm{wt}}$ alone, no splicing was observed (Fig. 4, lanes $1-5)$. However, when micrococcal nuclease (MN)-treated nuclear extract-in which all endogenous snRNPs were degraded-was added, splicing was observed, albeit at a lower level than observed with purified B complexes plus $\mathrm{MN}$-extract (Fig. 4, lanes 6-7 versus 13-14; where the average splicing product formation (from two independent experiments) \pm the s.d. was $3.9 \pm 0.5 \%$ for pre-B versus $18.4 \pm 2.6 \%$ for $B$ after $60 \mathrm{~min}$ ). Thus, purified pre-B complexes can be chased into mature spliceosomes that catalyse both steps of splicing. Splicing was not observed when pre-mRNA alone was incubated under splicing conditions with MN-treated extract (Fig. 4, lanes 15-17). The efficiency of the pre-B complex chase, but not that of $\mathrm{B}$ complexes, could be improved by adding an excess recombinant hPrp $28^{\mathrm{wt}}$ protein to the reaction (Fig. 4, lanes $8-9$ and Supplementary Fig. $4 ; 9.6 \pm 2.9 \%$ splicing product formation with pre-B plus MN extract and hPrp28 after $60 \mathrm{~min}$ ). This suggests that the lower splicing efficiency of pre-B complexes plus MN extract results from the inability of endogenous hPrp28 in the MN-treated extract to efficiently displace hPrp $28^{\mathrm{AAAD}}$.

The structures of the pre- $B$ and $B$ complex are different. The $37 \mathrm{~S}$ pre-B and $45 \mathrm{~S}$ B complexes exhibit very different sedimentation coefficients despite having very similar molecular masses, suggesting that they differ structurally. We thus analysed affinity-purified pre-B complexes stalled in the presence of 

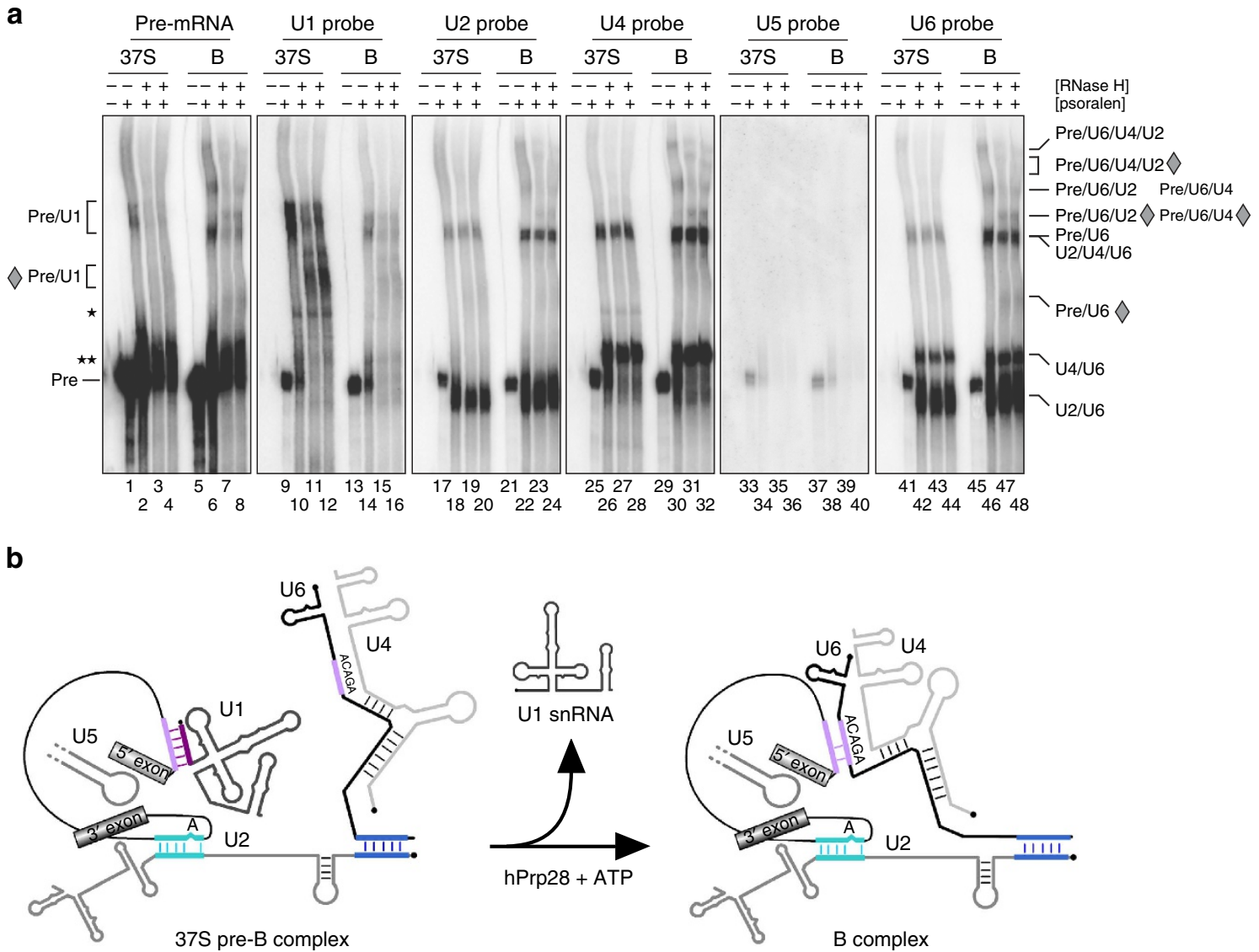

Figure 3 | Identification of RNA-RNA interactions in the $\mathbf{3 7 S}$ pre-B complex via psoralen crosslinking. (a) Affinity-purified pre-B and B complexes were UV-irradiated \pm psoralen (AMT) as indicated. Total psoralen-crosslinked RNA was incubated with RNase $\mathrm{H}$ and an oligonucleotide complementary to exon 2 of the MINX pre-mRNA as indicated above each lane. RNA-RNA crosslinks were identified by northern blot analyses, incubating sequentially with ${ }^{32}$ P-labelled probes against the pre-mRNA, and U1, U2, U4, U5 and U6 snRNAs. The blot was stripped of each ${ }^{32} \mathrm{P}$-probe before incubation with a subsequent probe. ${ }^{32} \mathrm{P}$-labelled MINX pre-mRNA, on which the pre-B and B complexes were formed, is visible in all panels. The lower intensity of the ${ }^{32} \mathrm{P}$-pre-mRNA in the U5 panel is due to decay of the original signal. The positions of crosslinked RNA species are indicated. Bands appearing after RNase $H$ digestion are indicated with a diamond $(\diamond)$. ${ }^{\star} A$ potential U1/U4 crosslink and ${ }^{\star \star}$ Internally crosslinked MINX pre-mRNA. (b) Schematic representation of the RNA-RNA networks in the pre-B and B complexes. The 5'ss base pairing interaction with U1 followed by U6 is highlighted purple, the U2-branch site base pairing interaction is shown in light blue and U2/U6 helix II is shown in dark blue.

hPrp28 $28^{A A A D}$ by negative-stain electron microscopy (EM) after gradient fixation (GraFix; Fig. 5). Well defined, single particles were visible in the EM overview (Fig. 5a). Classification and class averaging of single particle images (Fig. $5 \mathrm{~b}$ ) revealed that the pre$B$ complex possesses an upper head domain and an elongated body domain, and has a maximum length of $\sim 40 \mathrm{~nm}$. The head domain is triangular and appears similar in all classes. In contrast, the lower body domain shows significant differences in its structure, varying in size and form in almost all class averages, suggesting it is flexible or structurally heterogeneous (Fig. 5b). However, the different structures could potentially also reflect different orientations of the complex on the EM grid. In contrast, B complexes appear structurally homogenous with a characteristic orientation in almost all class averages and clearer structural details (Fig. 5c,d). Overall the B complex appears more compact with less conformational flexibility of the head domain compared with the pre-B complex, which might contribute to its higher $S$-value. The structure of pre-B in most classes is very different from that of $\mathrm{B}$, indicating that the pre- $\mathrm{B}$ to $\mathrm{B}$ complex transition is accompanied by a substantial structural rearrangement.

Tri-snRNP stabilization via addition of a 5'ss RNA in trans. We next tried to bypass the exchange of U1 for U6 at the $5^{\prime}$ ss, which is blocked in the pre-B complex due to the presence of hPrp $28^{A A A D}$, by adding an excess of an RNA oligonucleotide containing an optimized $5^{\prime}$ ss sequence (designated $5^{\prime}$ ss oligo). This $5^{\prime}$ ss oligo is complementary to the $5^{\prime}$ end of U1 snRNA, and to U6 snRNA (Supplementary Fig. 5a). When added in excess, it not only competes with the 5 'ss for U1 binding, thereby disrupting the $\mathrm{U} 1 / 5^{\prime}$ ss interaction, but also interacts with the U4/ U6.U5 tri-snRNP, in particular U6 snRNA 27,38 (Fig. 6a). However, a $2^{\prime} \mathrm{O}$-ribose methylated (2'Ome) version of this $5^{\prime} \mathrm{ss}$ oligo does not bind the tri-snRNP, and only leads to U1 displacement from the endogenous $5^{\prime}$ ss (ref. 38). When we assembled spliceosomes in nuclear extract in the presence of an inhibitory concentration of hPrp $28^{\mathrm{AAAD}}$ and subsequently added an excess of the $2^{\prime}$ Ome $5^{\prime}$ ss oligo, no B complex formation was observed (Fig. 6b). However, addition of the non-methylated form of the $5^{\prime}$ ss oligo led to B complex formation (Fig. 6b). To determine whether U1 was underrepresented in the spliceosomal complexes formed after addition of the wild-type and $2^{\prime}$ Ome $5^{\prime}$ ss oligo, we affinity-purified them. Analysis of their RNA compositions showed a clear reduction in $\mathrm{U} 1$, but not other snRNAs, comparable to that observed for U1 with the B complex (Supplementary Fig. 5b). Using ${ }^{32} \mathrm{P}$ end-labelled 5'ss RNA oligos, we also confirmed that the wild-type oligo, but not the $2^{\prime}$ Ome version, binds to affinity-purified pre-B complexes 


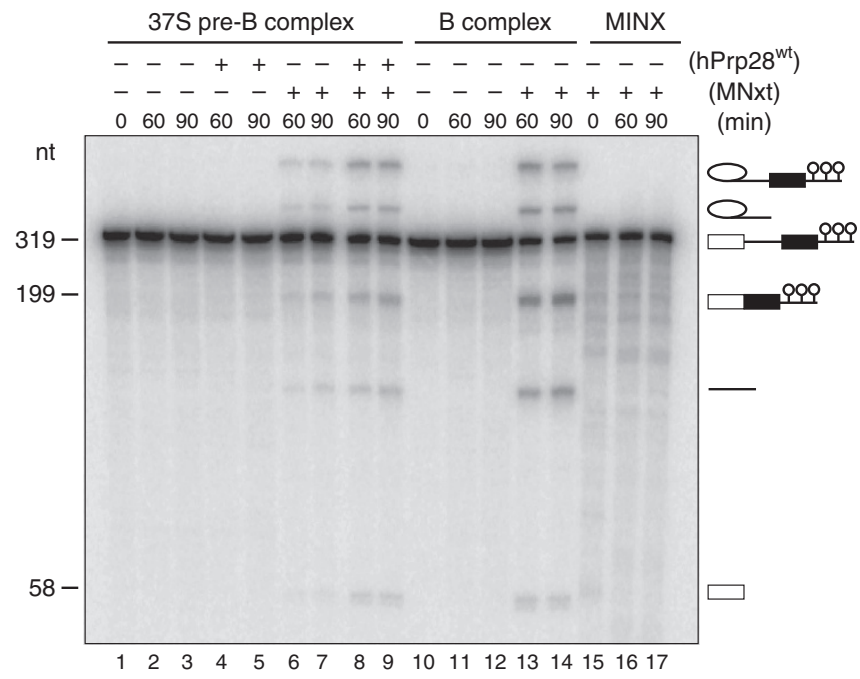

Figure 4 | Purified 37S pre-B complexes can be chased into catalytically active spliceosomes. Affinity-purified pre-B or B complexes, or MINX-MS2 pre-mRNA (as indicated above) were incubated at $30^{\circ} \mathrm{C}$ for the indicated times ( $0-90 \mathrm{~min}$ ) under splicing conditions in the presence of buffer alone (lanes 1-3 and 10-12) or micrococcal nuclease-treated HeLa nuclear extract (MNxt; lanes 6-9 and 13-17). To outcompete the hPrp28AAAD mutant present in the pre-B complexes, $50 \mathrm{ng} \mu \mathrm{l}^{-1}$ of recombinant hPrp28 ${ }^{\text {wt }}$ protein was added before incubation at $30^{\circ} \mathrm{C}$ (lanes $4-5$ and 8-9). RNA was analysed by denaturing PAGE and visualized with a Phosphorimager. The positions of the pre-mRNA, splicing intermediates and products are indicated on the right. Nucleotide length (nt) markers are derived from the snRNAs from purified human $37 \mathrm{~S}$ cross-exon complexes run in parallel.

(Supplementary Fig. 6), consistent with the former interacting with components of the tri-snRNP. Thus, displacement of U1 from the pre-mRNA's $5^{\prime}$ ss in the absence of hPrp28 activity is not sufficient to allow the loosely bound tri-snRNP in the pre-B complex to stably interact with the $5^{\prime}$ ss of the pre-mRNA.

We next tested whether stable tri-snRNP association can be induced by the $5^{\prime}$ ss oligo in the absence of nuclear extract. When affinity-purified, pre-B complexes were analysed on a glycerol gradient containing $150 \mathrm{mM} \mathrm{KCl}$ (Fig. 6c), the majority of the complexes peaked in fractions $10-12$ with an $S$-value $<30 S$ (Fig. 6c), consistent with dissociation of the U4/U6.U5 tri-snRNP under these conditions. Thus, affinity-purified pre-B complexes (that is, in the absence of nuclear extract) are not stable when subjected to a second glycerol gradient containing $150 \mathrm{mM}$ salt. However, addition of the $5^{\prime}$ ss oligo, but not the $2^{\prime}$ Ome form, led to the formation of a complex with a higher $S$-value that co-migrated with purified B complexes run in parallel. Affinity selection of this stabilized complex showed that it contains stoichiometric amounts of the U2 snRNP and U4/U6.U5 tri-snRNP, and the MINX-MS2 pre-mRNA, based on its RNA composition (Fig. 6d). Thus, addition of a 5 'ss oligo in trans leads to a more stably associated tri-snRNP and a shift in $S$-value even in the absence of extract, indicating that all factors required for tri-snRNP stabilization are already present in purified pre-B complexes. Thus, the B-specific proteins, which are for the most part absent from the pre-B complex, are not required for saltstable tri-snRNP integration.

EM of affinity-purified pre-B complexes incubated with the $5^{\prime}$ ss oligo in the absence of extract, showed well-defined single particles (Fig. 5e). The most frequently observed classes are very similar and show only a low degree of structural heterogeneity (Fig. 5f). The $5^{\prime}$ ss oligo stabilized pre-B complex adopts a structure almost identical to that of the B complex (Fig. $5 c, d$ ), with nearly no structural similarities with the pre-B complex (Fig. 5a,b). Thus, addition of an excess of a $5^{\prime}$ ss in trans induces a significant change in the structure of the $37 \mathrm{~S}$ pre-B complex such that it adopts an organization characteristic for B complexes with stably integrated tri-snRNP. This is consistent with the idea that the interaction of the tri-snRNP with a $5^{\prime}$ ss in trans mimicks the situation with the pre-mRNA, where the $5^{\prime}$ ss is present in cis. Taken together, our data indicate that a decisive factor for stable binding of the tri-snRNP during $\mathrm{B}$ complex formation is its interaction with the $5^{\prime}$ ss.

\section{Discussion}

Here we identify a spliceosome assembly intermediate formed before hPrp28 action, which to date has not been characterized in higher eukaryotes. Although the $37 \mathrm{~S}$ pre-B complex contains stoichiometric amounts of all five snRNAs, the tri-snRNP is not stably associated, indicating that association of the latter can occur before hPrp28 action, but its stable integration into the spliceosome requires ATP hydrolysis by hPrp28 (Fig. 1). The preB complex most likely previously escaped detection because it is relatively unstable and/or in the presence of wild-type hPrp28 is rapidly converted to a heparin-stable, spliceosomal B complex. Importantly, chase experiments with affinity-purified pre-B complexes and MN-treated nuclear extract (Fig. 4), demonstrated that it is a functional spliceosome assembly intermediate.

Affinity-purified pre-B complexes contained essentially all U1, U2, U4/U6 and U5 snRNP proteins (Fig. 2; Table 1; Supplementary Data 1). However, unlike the B complex, the pre-B complex contains stoichiometric amounts of hPrp4 kinase, RBM42 and U1 snRNP proteins, but only very low levels of the B-specific proteins RED, MFAP1, FBP21, hSmu-1, hPrp38 and $\mathrm{hSnu23.} \mathrm{As} \mathrm{hPrp4} \mathrm{kinase} \mathrm{is} \mathrm{not} \mathrm{present} \mathrm{in} \mathrm{human} \mathrm{spliceosomal} \mathrm{A}$ complexes and very little is detected in the $\mathrm{B}$ complex $^{26}$, this kinase appears to associate transiently with the spliceosome. Human Prp4 kinase phosphorylates the tri-snRNP proteins hPrp31 and hPrp6 during B complex formation, and is required for stable $\mathrm{B}$ complex formation in vitro ${ }^{35}$. As hPrp31 was only weakly phosphorylated in affinity-purified pre-B complexes (Supplementary Fig. 2), hPrp4 kinase appears to be inactive at this stage of spliceosome assembly. What triggers hPrp4 kinase activity and ultimately leads to its dissociation from the $\mathrm{B}$ complex is not clear. One possibility is that the conformational rearrangement that occurs during the pre- $\mathrm{B}$ to $\mathrm{B}$ transition (see below) might trigger hPrp4 kinase activity (or vice versa) and at the same time induce structural changes that result in its release. Consistent with this, addition of the 5'ss RNA oligo to extracts where pre-B complexes were first allowed to form (in the presence of $h \operatorname{Prp} 28^{\mathrm{AAAD}}$ ), leading to stable trisnRNP intergration and formation of a $45 \mathrm{~S}$ complex, also leads to enhanced phosphorylation of hPrp31 (Supplementary Fig. 2).

The structure of the $37 \mathrm{~S}$ pre-B complex differs from that of the 45S B complex (Fig. 5), indicating that a substantial rearrangement occurs before or during stable tri-snRNP integration during intron-defined spliceosome assembly. A structural change was also recently observed when a cross-exon splicing complex with loosely associated tri-snRNP was converted into a B-like complex with stably associated tri-snRNP ${ }^{38}$. Previously, immuno-EM studies indicated that the U2 snRNP is in the head domain of the B complex ${ }^{39}$, while U5 snRNP and U4/U6 snRNP are in the body and neck region, respectively ${ }^{40}$. Unfortunately, at the current resolution, it is not possible to assign the probable positions of the snRNPs to the $2 \mathrm{D}$ images of the pre-B complex. Initial attempts to localize the U2 or tri-snRNP via immuno-EM were unsuccessful due to the labile nature of the pre-B complex. Thus, it is presently not clear whether the tri-snRNP itself 


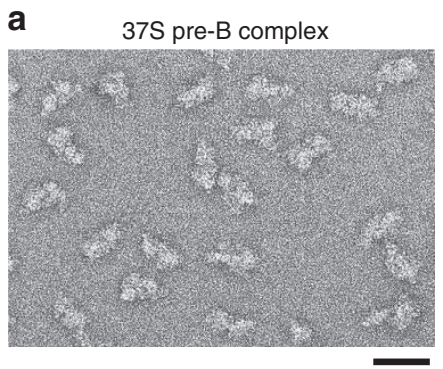

b

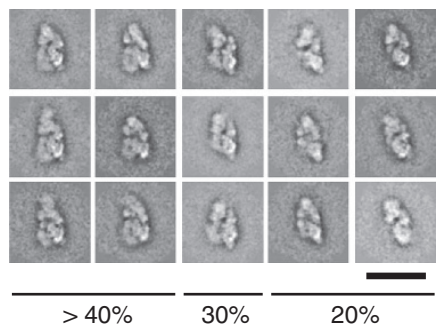

C

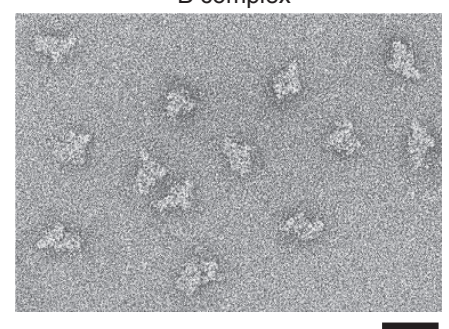

d

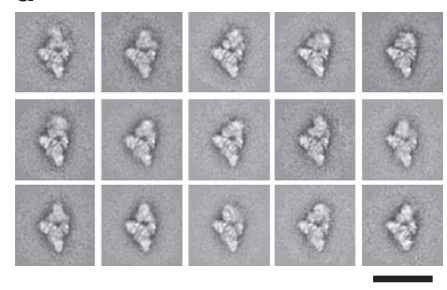

e $37 \mathrm{~S}$ pre-B complex +5 'ss oligo

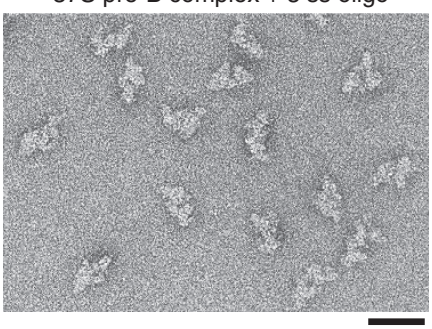

f

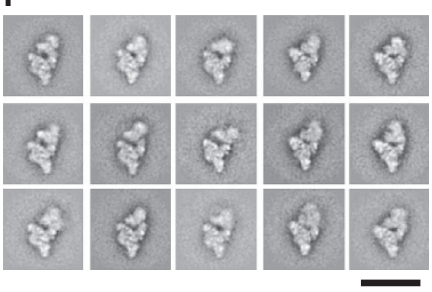

g
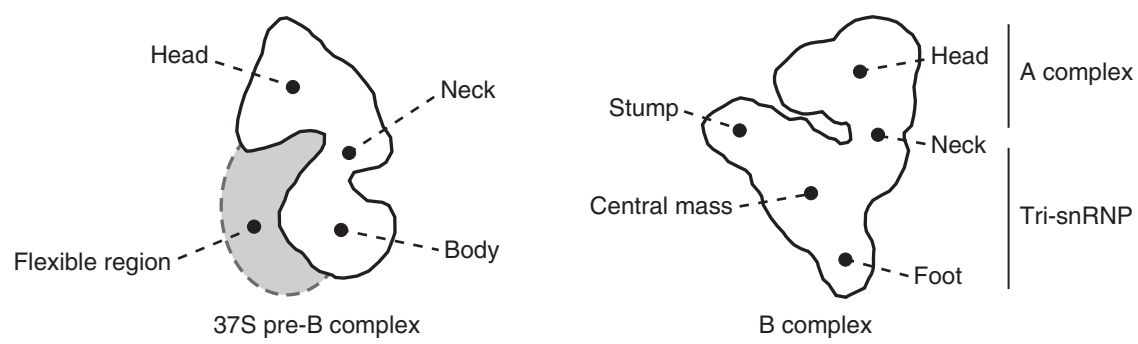

Figure 5 | Electron microscopy of the $\mathbf{3 7 S}$ pre-B complex. Overviews of negatively stained, affinity-purified $37 \mathrm{~S}$ pre-B (a) and B complexes (c) or affinitypurified 375 pre-B complexes incubated solely with the 5'ss RNA oligo (e). Representative class averages from 9,000 to 11,000 single-particle images of each complex are shown in the galleries in $\mathbf{b}, \mathbf{d}$ and $\mathbf{f}$. Scale bars, $50 \mathrm{~nm}$. (g) Schematic representation of the $37 \mathrm{~S}$ pre-B complex and B complex, with main structural features labelled according to Boehringer et al. ${ }^{52}$

undergoes an RNP rearrangement or alternatively that its position relative to components of the A complex has changed.

The identification and characterization of an assembly intermediate formed after A but before the pre-catalytic B complex, allows a more clear definition of what precisely a spliceosomal B complex is. Namely, our data demonstrate that the formation of a B complex requires ATP binding/hydrolysis by Prp28, during which U1 is displaced from the $5^{\prime}$ ss and replaced by U6 snRNA. At the same time a structural rearrangement occurs which leads to stable association of the tri-snRNP and recruitment of the B-specific proteins. The U4 and U6 snRNAs are still base-paired in the pre-catalytic B complex, keeping U6 in an inactive state ${ }^{41}$. The displacement of U1 by Prp28 occurs before or during B complex formation, whereas release of U4 by the helicase Brr2 occurs during the subsequent spliceosome activation step (Fig. 7). Thus, these two spliceosomal helicases act sequentially and, although displacement of $\mathrm{U} 1$ from the 5 'ss may be a prerequisite for activation, they apparently do not necessarily act in a coordinated fashion.

Interestingly, the $37 \mathrm{~S}$ pre-B complex, which is an early intermediate of the cross-intron spliceosomal assembly pathway, shares similarities but also differences with the recently described $37 \mathrm{~S}$ cross-exon complex ${ }^{27,38}$. The latter forms on an exon containing solely flanking intron sequences, and is an early intermediate of the cross-exon spliceosome assembly pathway. Both complexes share nearly identical protein and snRNA compositions, containing $\mathrm{U} 1$ and $\mathrm{U} 2 \mathrm{snRNP}$, and loosely associated tri-snRNP (Fig. 2) ${ }^{38}$. However, despite nearly identical compositions, each complex appears to have a distinct morphology as evidenced by EM (Supplementary Fig. 7). This apparent structural difference might reflect the different location of U1 snRNP relative to the BPS-bound U2 snRNP in both complexes; U1 is base-paired with the $5^{\prime}$ ss upstream of the BPS in the $37 \mathrm{~S}$ pre- $\mathrm{B}$ complex, whereas in the $37 \mathrm{~S}$ cross-exon complex it is bound to the $5^{\prime}$ ss downstream of the BPS and the exon. It will be interesting to compare the three-dimensional structure of these complexes by cryo-EM in the future, to more clearly elucidate any structural differences.

Stable tri-snRNP association with the $37 \mathrm{~S}$ cross-exon complex can be achieved by adding a 5'ss-containing RNA oligonucleotide in trans-either to splicing extract or to affinity-purified crossexon complexes, and is accompanied by a major structural change that generates a complex (the so-called B-like complex) with a morphology highly similar to the B complex (Supplementary Fig. 5) ${ }^{27,38}$. We observed a similar effect with $37 \mathrm{~S}$ pre-B complexes. Namely, addition of the 5 'ss oligo to splicing extracts containing inhibitory concentrations of hPrp $28^{A A A D}$ or to affinity-purified $37 \mathrm{~S}$ pre-B complexes led to the formation of a complex with stably associated tri-snRNP (Fig. 6), which appears to be structurally very similar to the B complex, as evidenced by EM (Fig. 5; Supplementary Fig. 7). This is consistent with the idea that the $37 \mathrm{~S}$ complexes with loosely associated U4/U6.U5 tri-snRNP represent a very similar intermediate in both the exon-defined and intron-defined spliceosome assembly pathways, and that stable tri-snRNP integration is triggered by its interaction with the pre-mRNA's $5^{\prime}$ ss in both pathways. They further suggest that the exon- and intron-defined spliceosome assembly pathways converge at the $\mathrm{B}$ 
a

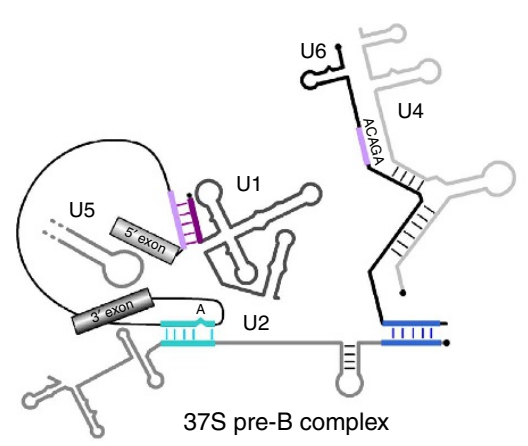

b

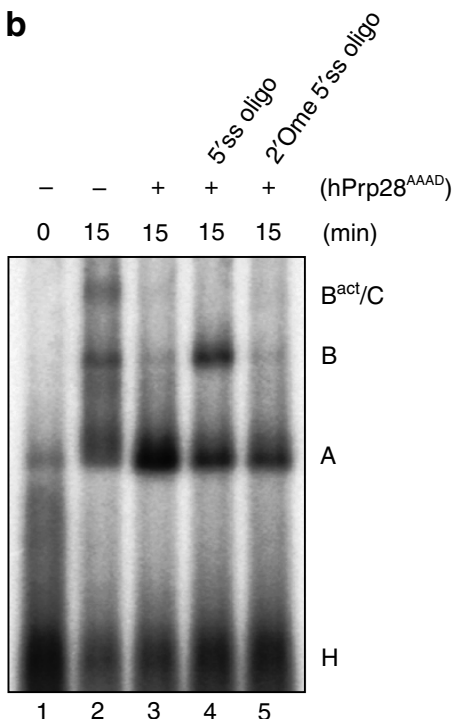

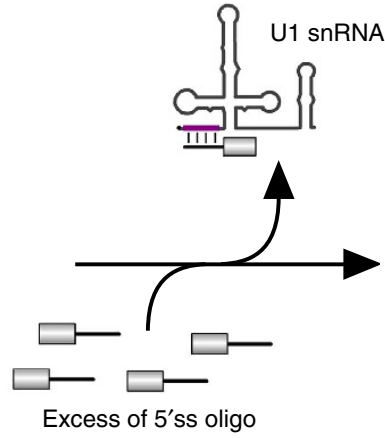

Excess of 5'ss oligo

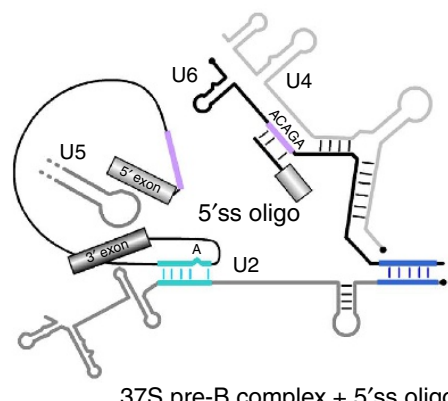

d
C

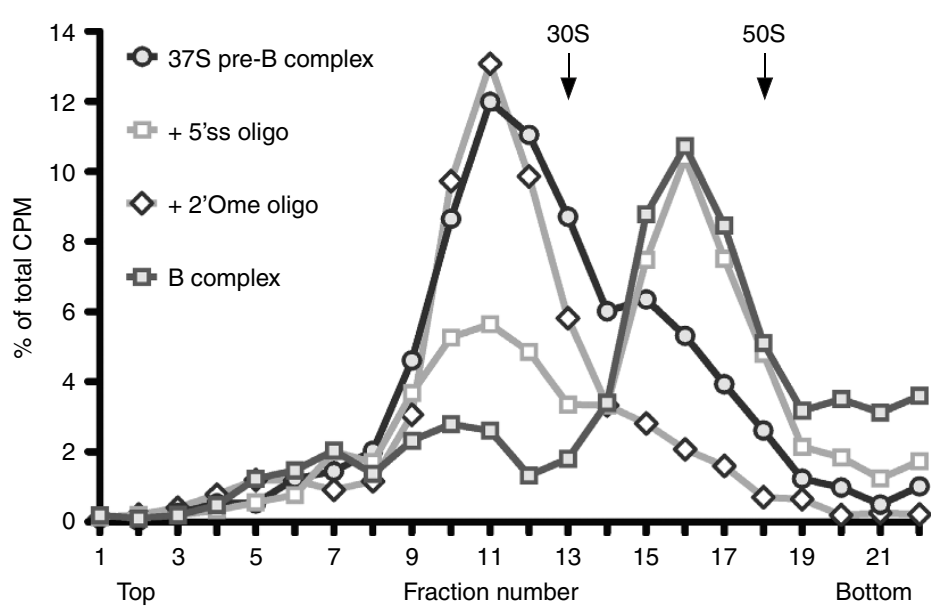

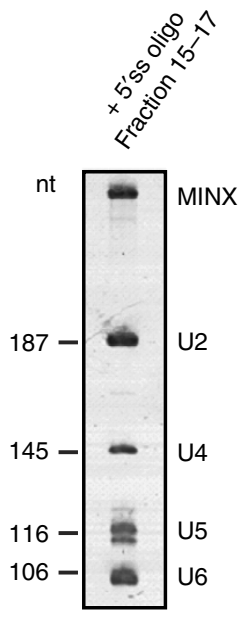

Figure 6 | Addition of a 5'ss RNA oligonucleotide to 37S pre-B complexes induces stable tri-snRNP binding. (a) Schematic of the effect of the addition of an excess of a 5'ss containing oligonucleotide on RNA-RNA interaction within the pre-B complex. Colouring as in Fig. 3. (b) $37 \mathrm{~S}$ pre-B complexes were assembled in nuclear extract on ${ }^{32} \mathrm{P}$-labelled MINX-MS2 pre-mRNA in the presence of an inhibitory concentration of hPrp28 ${ }^{A A A D}$. After 3 min, wild type or $2^{\prime}$ Ome $5^{\prime}$ ss oligo was added at an 100-fold excess. Splicing complex formation was analysed on an agarose gel in the presence of heparin and visualized by autoradiography. The positions of $\mathrm{H}, \mathrm{A}, \mathrm{B}$ and $\mathrm{B}^{\mathrm{act}} / \mathrm{C}$ complexes are indicated. (c) Glycerol gradient centrifugation $(150 \mathrm{mM} \mathrm{KCl})$ of affinity-purified $37 \mathrm{~S}$ pre-B complexes alone or after incubating with either a wild-type 5'ss RNA oligonucleotide or a 2'Ome version thereof. Affinity-purified B complexes were run in parallel. The percent of total radioactivity ( ${ }^{32} \mathrm{P}-\mathrm{MINX}$ pre-mRNA) is plotted for each gradient fraction. (d) RNA was recovered from the indicated peak fractions, separated by denaturing PAGE and visualized by silver staining. Identities of snRNAs are indicated. Nucleotide length (nt) markers are derived from the spliceosomal snRNAs from purified human $37 \mathrm{~S}$ cross-exon complexes run in parallel.

complex stage. Indeed, as splicing catalysis can only occur across an intron, cross-exon complexes must be converted to crossintron complexes before catalysis.

As affinity-purified pre-B complexes contain only very low levels of B-specific proteins, we conclude that they are not essential for stable integration of the U4/U6.U5 tri-snRNP during B complex formation. Transformation of $37 \mathrm{~S}$ cross-exon complexes with loosely associated tri-snRNP, to B-like complexes with stably integrated tri-snRNP, also did not require B-specific proteins, indicating that they also do not contribute substantially to stable tri-snRNP binding during this transition ${ }^{38}$. Instead, B-specific proteins appear to function after B complex formation and thus likely contribute to the subsequent activation step, during which they are displaced from the spliceosome.

Our data provide important insights into hPrp28's role during mammalian splicing. Human Prp28 is still present in stoichiometric amounts in affinity-purified pre- $\mathrm{B}$ complexes and the vast majority that is present is the $\mathrm{hPrp} 28^{\mathrm{AAAD}}$ mutant (Fig. 2; Supplementary Fig. 2). Thus, the latter outcompetes the endogenous wild-type protein for binding to the spliceosome. Given that the DEAD to AAAD exchange has little or no effect on the overall structure of the mutant protein, it is likely that it is incorporated in the spliceosome in an identical manner, establishing the same RNA and protein contacts. Thus, the defect in spliceosome assembly is not due to the absence of hPrp28 nor apparently to its aberrant incorporation into the trisnRNP/spliceosome, but rather most likely due to its lack of ATPase/unwinding activity.

The $h \operatorname{Prp} 28^{\mathrm{AAAD}}$-mediated block in spliceosome assembly occurs before disruption of the U1/5'ss interaction (Fig. 3). Thus, ATP hydrolysis by $\mathrm{hPrp} 28$ is also a prerequisite for displacement of U1 from the $5^{\prime}$ ss in higher eukaryotes. As the U1/5'ss and U6/ 5 'ss interactions are mutually exclusive, the latter interaction can only occur within the spliceosome if U1 has vacated the $5^{\prime} \mathrm{ss}$. Interestingly, addition of a $2^{\prime} \mathrm{Ome} 5^{\prime}$ ss oligo to a splicing reaction containing inhibitory amounts of $h \operatorname{Prp} 28^{\mathrm{AAAD}}$, did not support $\mathrm{B}$ complex formation (Fig. 6), even though it led to displacement of the majority of U1 from the pre-mRNA (Supplementary Fig. 5). Thus, an accessible $5^{\prime}$ ss present in cis is apparently not sufficient to trigger stable tri-snRNP integration nor the structural change converting the spliceosome from a $37 \mathrm{~S}$ to $45 \mathrm{~S}$ complex. This suggests that in the spliceosome $h \operatorname{Prp} 28$ may play an 


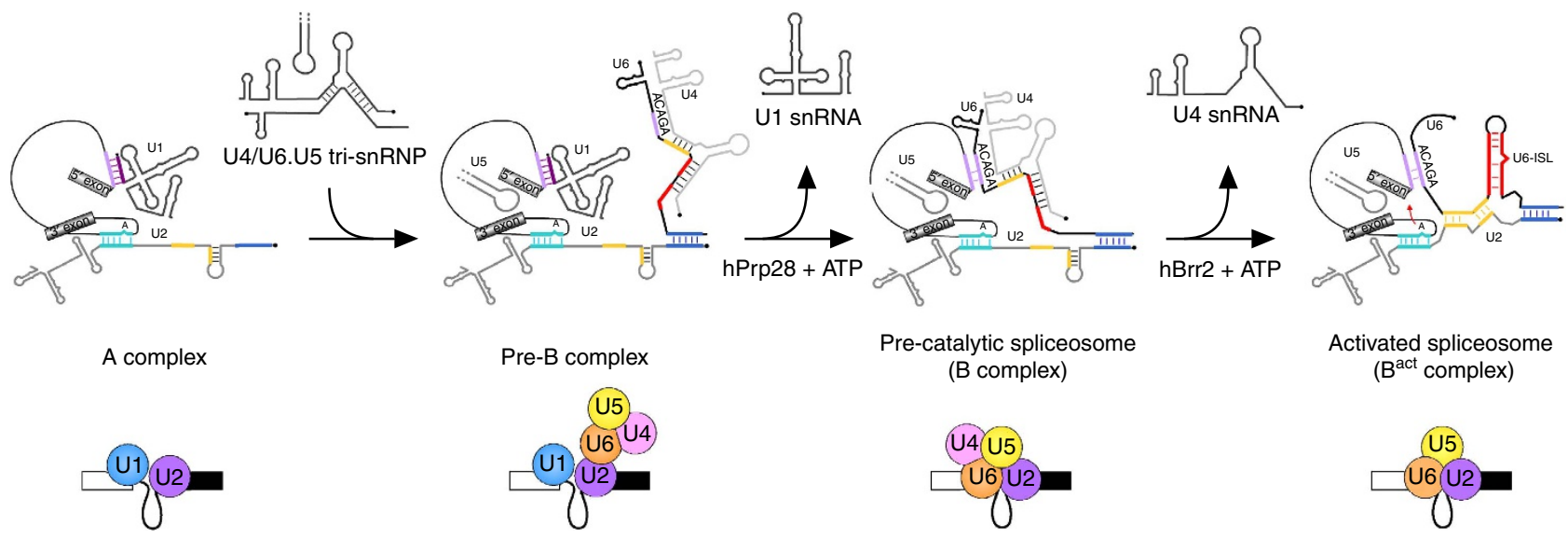

Figure 7 | Summary of the cross-intron spliceosome assembly pathway. The A, pre-B, B and $B^{\text {act }}$ complexes and their RNA-RNA networks are shown schematically. The $5^{\prime}$ ss base pairing interaction with U1 followed by U6 is highlighted purple, the U2-branch site base pairing interaction is shown in light blue, U2/U6 helix II is shown in dark blue and U2/U6 helix I is shown in yellow.

additional role. Crosslinking studies showed that in the human $\mathrm{B}$ complex, the ATP-binding site of hPrp28 is close to the $5^{\prime}$ ss, just a few nucleotides downstream of the exon-intron junction, which is contacted by hPrp8, and that ATP hydrolysis is required for hPrp28 interaction with the $5^{\prime}$ ss (ref. 31 ). It was thus proposed that hPrp28 not only unwinds the U1/5'ss duplex but also facilitates a conformational change that positions the $5^{\prime}$ ss for base pairing with the U6 ACAGA box ${ }^{31}$. Although this coordinated handoff appears to be circumvented, at least partially, by adding an excess of an unmodified $5^{\prime}$ ss containing oligo that can base pair with U6 in the absence of Prp28 activity and thereby trigger stable tri-snRNP binding (Fig. 6), this is not likely the case within the spliceosome. Recent studies investigating stable tri-snRNP integration after its initial association with a cross-exon spliceosomal complex, indicated that a major determinant for stable tri-snRNP integration is the interaction of Prp8 with the $5^{\prime}$ ss (ref. 38). Thus, hPrp28 action may also position the $5^{\prime}$ ss for interaction with Prp8, leading to stable tri-snRNP integration and formation of the B complex. Consistent with this, S. cerevisiae Prp28 interacts genetically with Prp8 (ref. 42). Such a coordinated handover of the $5^{\prime}$ ss from U1 to hPrp8/U6 by hPrp28 potentially contributes to the high fidelity of $5^{\prime}$ ss recognition. Indeed, genetic studies in yeast indicate that $\operatorname{Prp} 28$ proofreads the $5^{\prime}$ ss and ultimately rejects poor $5^{\prime}$ splice sites ${ }^{15}$.

Human Prp28 adopts an active conformation first when incorporated into the spliceosome ${ }^{16}$. Our data suggest that initial docking of the tri-snRNP to the A complex may already trigger a conformational change in Prp28, thereby activating it, as $\mathrm{hPrp} 28^{\prime} \mathrm{s}$ ATPase activity is required for the subsequent assembly step that generates complex B. As the transition from a pre-B to B complex involves a major structural change (Fig. 5), which appears to require the interaction of $\operatorname{Prp} 8 / \mathrm{U} 6$ with the $5^{\prime} \mathrm{ss}$ (ref. 38; Fig. 6), it is tempting to speculate that this structural change is mediated/triggered by $\mathrm{hPrp} 28^{\prime} \mathrm{s}$ ATPase/unwinding activity.

\section{Methods}

Purification of recombinant hPrp28 protein. N-terminally $\mathrm{His}_{6}$-tagged hPrp28 and hPrp28 $8^{\mathrm{AAAD}}$ were expressed in Escherichia coli Rosetta 2 (DE3) cells ${ }^{20}$. Cells were grown to an $\mathrm{OD}_{600}$ of $0.4-0.8$ at $30^{\circ} \mathrm{C}$ and expression of the recombinant protein was induced by adding $0.3 \mathrm{mM}$ IPTG. After incubation at $18^{\circ} \mathrm{C}$ overnight,

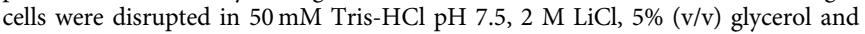
$2 \mathrm{mM} 2$-mercaptoethanol in the presence of a protease inhibitor cocktail (ALP) using a microfluidizer (M-110S, Microfluidics). After centrifuging at 35,000 $\mathrm{g}$ for $30 \mathrm{~min}$, the supernatant was loaded onto a Ni-NTA Sepharose column (Protino, Macherey and Nagel) in buffer containing $50 \mathrm{mM}$ Tris/ $\mathrm{HCl} \mathrm{pH} \mathrm{7.5,500} \mathrm{mM} \mathrm{NaCl}$, $5 \%(\mathrm{v} / \mathrm{v})$ glycerol, $2 \mathrm{mM} 2$-mercaptoethanol and $10 \mathrm{mM}$ imidazole. After washing,
His $_{6}$-hPrp28 or $\mathrm{His}_{6}$-hPrp28 $28^{\mathrm{AAAD}}$ was eluted by gradually increasing the concentration of imidazole to $300 \mathrm{mM}$. After sample concentration, purification to homogeneity was achieved by size exclusion chromatography (Superdex 200, GE Healthcare) performed in $10 \mathrm{mM}$ Tris- $\mathrm{HCl} \mathrm{pH} 7.5,500 \mathrm{mM} \mathrm{NaCl}, 5 \%(\mathrm{v} / \mathrm{v})$ glycerol and $2 \mathrm{mM}$ 2-mercaptoethanol.

Pre-mRNA splicing and splicing complex formation. Splicing reactions contained $40 \%$ (v/v) HeLa nuclear extract ${ }^{43}, 65 \mathrm{mM} \mathrm{KCl}, 3 \mathrm{mM} \mathrm{MgCl}_{2}, 2 \mathrm{mM} \mathrm{ATP}$, $20 \mathrm{mM}$ creatine phosphate and $10 \mathrm{nM}$ uniformly ${ }^{32} \mathrm{P}$-labelled, $\mathrm{m}^{7} \mathrm{G}$-capped MINXMS2 pre-mRNA, and were incubated at $30^{\circ} \mathrm{C}$ for the indicated times. To test the effect of recombinant hPrp28 on splicing, reactions were supplemented with $\mathrm{His}_{6}{ }^{-}$ tagged wild-type hPrp 28 or mutant hPrp $28^{\mathrm{AAAD}}$ to a final concentration of 10-100 $\mathrm{ng}^{-1}$ before the addition of the pre-mRNA and preincubated for $30 \mathrm{~min}$ at $30^{\circ} \mathrm{C}$ to allow an exchange of the recombinant protein with the endogenous hPrp28. Splicing was initiated by addition of the radiolabelled MINX-MS2 pre-mRNA. RNA was recovered at the indicated time points and separated on a $14 \%$ polyacrylamide gel containing $6 \mathrm{M}$ urea. Unspliced pre-mRNA, and splicing intermediates and products were detected using a Typhoon phosphoimager (GE Healthcare). The pre-mRNA, and splicing intermediates and products (spliced mRNA and excised lariat intron) were quantified using ImageQuantTL (GE Healthcare). The percent spliced mRNA was calculated by dividing the amount of mRNA by the amount of pre-mRNA, lariat-intermediate and splicing products (minus background), and multiplying by 100 . To investigate the effect of a 5 'ss-containing RNA added in trans, splicing reactions containing an inhibitory concentration $\left(50 \mathrm{ng} \mathrm{hl}^{-1}\right)$ of hPrp $28^{\mathrm{AAAD}}$ were first incubated for $3 \mathrm{~min}$ at $30^{\circ} \mathrm{C}$. The reaction was then supplemented with an RNA oligonucleotide containing a $5^{\prime}$ ss (5'-AAG/GUAAGUAU-3', Eurofins MWG Operon) or a 2'O-ribose methylated version thereof, to a final concentration of $1 \mu \mathrm{M}$ followed by an additional incubation at $30^{\circ} \mathrm{C}$ for $15 \mathrm{~min}$. Spliceosomal complexes were analysed on a $2 \%(\mathrm{w} / \mathrm{v})$ low melting point agarose gel in the presence of $0.65 \mathrm{mg} \mathrm{ml}^{-1}$ heparin $^{44}$ and bands were visualized with a Typhoon phosphoimager (GE Healthcare). Alternatively, splicing reactions were loaded onto a linear 10-30\% (v/v) glycerol gradient containing G-150 buffer (20 mM Hepes-KOH pH 7.9, $1.5 \mathrm{mM} \mathrm{MgCl}_{2}, 150 \mathrm{mM} \mathrm{KCl}$ ) or G-75 buffer (G-buffer with $75 \mathrm{mM} \mathrm{KCl}$ ) as indicated, and centrifuged at $488,576 \mathrm{~g}\left(r_{\max }\right)$ for $135 \mathrm{~min}$ at $4{ }^{\circ} \mathrm{C}$ in a Sorvall TH660 rotor. The gradients were harvested manually in $175 \mu \mathrm{l}$ fractions from the top and the distribution of ${ }^{32} \mathrm{P}$-labelled MINX pre-mRNA was determined by Cherenkov counting.

Affinity purification of spliceosomal complexes. In vitro assembled spliceosomal complexes were purified by gradient centrifugation, followed by MS2 affinity selection $^{25,38}$. For this purpose, the ${ }^{32} \mathrm{P}$-labelled, MINX-MS2 pre-mRNA was incubated with a 20-fold molar excess of purified MS2-MBP fusion protein for $30 \mathrm{~min}$ at $4{ }^{\circ} \mathrm{C}$ before addition to the splicing reaction. B complexes were isolated after incubating a standard splicing reaction for $6 \mathrm{~min}$ at $30^{\circ} \mathrm{C}$; thus these kinetically stalled B complexes also contain low amounts of complexes formed before and after $\mathrm{B}$, including pre- $\mathrm{B}$ and $\mathrm{B}^{\text {act }}$ complexes, that migrate in the same position or close to $\mathrm{B}$ complexes on the glycerol gradient. Pre-B complexes were isolated after preincubation with $50 \mathrm{ng} \mathrm{Hl}^{-1}$ of hPrp $28^{\mathrm{AAAD}}$ protein. The splicing reactions were loaded onto a linear $10-30 \%(\mathrm{v} / \mathrm{v})$ glycerol gradient containing G-150 buffer and centrifugation was performed at $112,000 \mathrm{~g}\left(r_{\max }\right)$ for $15 \mathrm{~h}$ at $4{ }^{\circ} \mathrm{C}$ in a Sorvall TST 41.14 rotor. Gradients were harvested manually in $500 \mu$ l fractions from top to bottom. The distribution of ${ }^{32} \mathrm{P}$-labelled MINX-MS2 pre-mRNA across the gradient was determined by Cherenkov counting. Peak fractions containing spliceosomal complexes were pooled and loaded onto a column containing $150 \mu \mathrm{l}$ 
(packed volume) of amylose beads (NEB). After washing with G75 buffer, bound complexes were eluted with $300 \mu \mathrm{l}$ of G-75 buffer containing $20 \mathrm{mM}$ maltose. RNA was recovered from the purified complexes, separated on a denaturing polyacrylamide gel and visualized by silver staining.

2D gel electrophoresis and mass spectrometry. Affinity-purified, $37 \mathrm{~S}$ pre- $\mathrm{B}$ complexes were concentrated by sedimentation at 700,000 $\mathrm{g}$ and RNA was subsequently digested with RNase T1, RNase A and RNase I in the presence of urea ${ }^{26}$. After treatment with iodoacetamide to prevent protein oxidation, the sample was concentrated by dialysis against Slide-A-Lyser Concentration solution (Pierce) and loaded onto the first dimension. The first dimension gel contained $2 \%(\mathrm{w} / \mathrm{v})$ acrylamide, $1.4 \%$ methylene bisacrylamide, $7 \mathrm{M}$ urea, $4 \mathrm{M}$ thiourea, $40 \%(\mathrm{v} / \mathrm{v})$ formamide in $40 \mathrm{mM}$ Bis-TRIS-OAc pH 5.7 (ref. 26). The second dimension gel contained $8 \%(\mathrm{v} / \mathrm{v})$ acrylamide. Proteins were stained with RuBPS (RubiLAB) or, for mass spectrometry, with Coomassie. Protein spots were cut out of the 2D gel and proteins were digested in-gel with trypsin. Peptides were extracted and then analysed in a liquid-chromatography-coupled electrospray ionization quadruple time-of-flight mass spectrometer (LTQ Oribitrap XL) under standard conditions. Proteins were identified by searching fragment spectra against the NCBI nonredundant database using Mascot as a search engine. Psoralen crosslinking. Affinity-purified spliceosomal complexes (formed on
${ }^{32}$ P-labelled MINX pre-mRNA) in G150 buffer were supplemented with $40 \mu \mathrm{g} \mathrm{ml}^{-1}$ of AMT hydrochloride ${ }^{45}$. After incubating for $10 \mathrm{~min}$ on ice, samples ( \pm AMT) were irradiated with $365 \mathrm{~nm}$ ultraviolet light for $30 \mathrm{~min}$ at $4{ }^{\circ} \mathrm{C}$ with a distance of $4 \mathrm{~cm}$ between the samples and ultraviolet lamp. To further characterize the crosslinked RNA species, a 300- or 600-fold molar excess of a DNA oligo (5'-GTCCTCAACCGCGAG-3', Eurofins MWG Operon), complementary to nucleotides $1-15$ of the second exon of the MINX-MS2 pre-mRNA, and $0.1 \mathrm{U}_{\mu \mathrm{l}^{-1}}$ RNase H (NEB), were added to the crosslinked RNAs and the reaction was incubated for $1 \mathrm{~h}$ at $37^{\circ} \mathrm{C}$. RNA was resolved on a $5 \%$ polyacrylamide gel containing $6 \mathrm{M}$ urea and transferred to a nylon membrane (Hybond XL, GE Healthcare). The membrane was sequentially hybridized with ${ }^{32} \mathrm{P}$-labelled probes against the pre-mRNA, and the U1, U2, U4, U5 and U6 snRNAs. Before incubation with a different probe, ${ }^{32} \mathrm{P}$-labelled probe was removed by boiling the membrane for $30 \mathrm{~min}$ in $15 \mathrm{mM} \mathrm{NaCl}, 1.5 \mathrm{mM}$ sodium citrate and $0.1 \%$ (w/v) SDS; efficient probe removal was controlled using a Typhoon phosphoimager (GE Healthcare). The snRNA composition of the affinity-purified pre- $\mathrm{B}$ and $\mathrm{B}$ complexes used for psoralen crosslinking was checked via silver staining to ensure the identity and quality of the analysed complexes.

Chasing of affinity-purified pre-B complexes. HeLa nuclear extract was incubated with 0.5 units per $\mu \mathrm{l}$ of micrococcal nuclease (USB Affimetrix) and $1.6 \mathrm{mM}$ $\mathrm{CaCl}_{2}$ at $30^{\circ} \mathrm{C}$ for $6 \mathrm{~min}$. To inactivate the MN, EGTA was added to a final concentration of $4.5 \mathrm{mM}$. Affinity-purified $37 \mathrm{~S}$ pre-B or $45 \mathrm{~S}$ B complexes formed on ${ }^{32} \mathrm{P}$-labelled MINX-MS2 pre-mRNA were incubated with splicing buffer alone ( $70 \mathrm{mM} \mathrm{KCl}, 3 \mathrm{mM} \mathrm{MgCl}$, $2 \mathrm{mM}$ ATP, $20 \mathrm{mM}$ creatine phosphate), $50 \mathrm{ng} \mathrm{ll}^{-1}$ recombinant $\mathrm{hPrp} 28^{\mathrm{wt}}$ or additionally in the presence of $30 \%(\mathrm{v} / \mathrm{v})$ MN-treated HeLa nuclear extract $\pm 50 \mathrm{ng}^{-1} \mathrm{l}^{-1}$ recombinant hPrp28 $8^{\mathrm{wt}}$ (as indicated). A 10 -fold excess of unlabelled MINX-MS2 pre-mRNA was added to exclude the reassembly of snRNPs on the radiolabelled pre-mRNA in the event that they dissociate from the affinity-purified $37 \mathrm{~S}$ pre- $\mathrm{B}$ complexes. After incubation for $30 \mathrm{~min}$ on ice, the reaction was incubated at $30^{\circ} \mathrm{C}$ for $0-90 \mathrm{~min}$. RNA was recovered, separated on a $14 \%$ polyacrylamide gel containing $6 \mathrm{M}$ urea, and visualized with a Typhoon phosphoimager (GE Healthcare).

Stabilization of affinity-purified $37 \mathrm{~S}$ pre-B complexes. MS2 affinity-purified $37 \mathrm{~S}$ pre-B complexes in G-75 buffer were first supplemented with a 100 -fold excess of either the 5'ss RNA oligonucleotide or its $2^{\prime} \mathrm{O}$-ribose methylated version, and then incubated for $15 \mathrm{~min}$ on ice. The reaction was loaded onto a linear $10-30 \%$ $(\mathrm{v} / \mathrm{v})$ glycerol gradient containing G-150 buffer, and centrifuged at 488,576g $\left(r_{\max }\right)$ for $135 \mathrm{~min}$ at $4{ }^{\circ} \mathrm{C}$ in a Sorvall TH660 rotor. The gradients were harvested manually in $175 \mu \mathrm{l}$ fractions from the top and peak fractions were subjected to a second MS2 affinity selection. RNA was recovered from the affinity-purified complexes, separated on a denaturing polyacrylamide gel and visualized by silver staining.

Electron microscopy. For electron microscopy, affinity-purified complexes were subjected to a second, linear 10-30\% (v/v) glycerol gradient containing G-75 (37S pre-B complex) or G-150 (B complex and purified $37 \mathrm{~S}$ pre-B $+5^{\prime}$ ss oligo complex) buffer and $0-0.1 \%(\mathrm{v} / \mathrm{v})$ glutaraldehyde ${ }^{46}$. The samples were centrifuged at $488,576 \mathrm{~g}$ $\left(r_{\max }\right)$ for $2 \mathrm{~h}$ in a Sorvall TH660 rotor at $4{ }^{\circ} \mathrm{C}$ and gradients were harvested manually in $175 \mu \mathrm{l}$ fractions from the top. Particles were negatively stained by the single-carbon film method ${ }^{47}$. Images were recorded at a magnification of $\times 88,000$ at $160 \mathrm{kV}$ with a CM200 FEG electron microscope (Philips, The Netherlands) at room temperature and two-fold binning on a $4 \mathrm{k} \times 4 \mathrm{k}$ CCD camera (TVIPS, Germany). For each data set, 9,000-11,000 individual single-particle images were collected and single-particle image-processing was performed using the software package IMAGIC-5 (ref. 48). Image-processing consisted of a reference-free alignment, after which the images were subjected to multivariate statistical analysis and classification ${ }^{49-51}$. The resulting class averages were used as reference images for subsequent rounds of alignment until the class averages were stable.

Western blotting. For western blotting, proteins of affinity-purified complexes were separated by SDS-polyacrylamide gel electrophoresis (PAGE) and transferred to a nitrocellulose membrane (Protran, Whatman). The membrane was incubated in TBS buffer (50 mM Tris- $\mathrm{HCl} \mathrm{pH} 7.5,150 \mathrm{mM} \mathrm{NaCl}, 1 \%$ (v/v) Tween-20) containing 5\% (w/v) dried milk, with antibodies against hPrp28 (ref. 20), hSnu114 (ref. 51), $\mathrm{His}_{6}$-tag (Qiagen, catalogue number 34660), hPrp31 (ref. 35) or phosphorylated hPrp31 (ref. 35), and bound antibody was detected using an ECL detection kit (GE Healthcare). After sequential incubation with $\mathrm{His}_{6}$-tag $(1: 2,000)$ phosphorylated hPrp31 (1:5,000) and then hSnul14 $(1: 6,000)$ antibodies, bound antibodies were removed from the blot by incubating in S-buffer $(62.5 \mathrm{mM}$ Tris$\mathrm{HCl} \mathrm{pH} \mathrm{6.7,} \mathrm{2 \%} \mathrm{(w/v)} \mathrm{SDS,} 100 \mathrm{mM} \beta$-mercaptoethanol) at $50^{\circ} \mathrm{C}$ for $30 \mathrm{~min}$. The blot was then incubated with anti-hPrp28 $(1: 1,000)$ followed by anti-hPrp31 $(1: 1,000)$ antibodies. See Supplementary Fig. 8 for uncropped western blot images.

Copurification of 5'ss RNA oligonucleotide with spliceosomes. To determine whether the $5^{\prime}$ ss-containing oligonucleotides bind to spliceosomal complexes, unmodified or $2^{\prime} \mathrm{O}$-ribose methylated $5^{\prime}$ ss RNA oligonucleotide were first radioactively labelled at their $5^{\prime}$-end using $\gamma_{-}{ }^{32} \mathrm{P}$-ATP and T4 polynucleotide kinase. Spliceosomal complexes were allowed to form for $3 \mathrm{~min}$ at $30^{\circ} \mathrm{C}$, then a 100 -fold molar excess (relative to the MINX-MS2 pre-mRNA) of radiolabelled 5'ss oligonucleotide was added to the reaction. After an additional incubation of 3 min at $30^{\circ} \mathrm{C}$, spliceosomal complexes were purified by $10-30 \%(\mathrm{v} / \mathrm{v})$ glycerol gradient centrifugation and MS2 affinity-selection. RNA was recovered from the eluates, separated by denaturing PAGE and visualized by autoradiography. The specific activity of the $5^{\prime}$ ss oligonucleotides was 30,000 c.p.m. per pmol, whereas that of the MINX-MS2 pre-mRNA was 56,000 c.p.m. per pmol. The relative intensity of the 5 'ss oligo and the MINX-MS2 pre-mRNA in lane 2 was quantified using a Phosphorimager and ImageQuantTL (GE Healthcare).

Data availability. The authors declare that the data supporting the findings of this study are available within the article and its Supplementary Information files.

\section{References}

1. Will, C. L. \& Lührmann, R. Spliceosome structure and function. Cold Spring Harb. Perspect. Biol. 3, doi:10.1101/cshperspect.a003707 (2011).

2. Robberson, B. L., Cote, G. J. \& Berget, S. M. Exon definition may facilitate splice site selection in RNAs with multiple exons. Mol. Cell Biol. 10, 84-94 (1990).

3. Wahl, M. C., Will, C. L. \& Lührmann, R. The spliceosome: design principles of a dynamic RNP machine. Cell 136, 701-718 (2009).

4. Nilsen, T. W. RNA Structure and Function 279-307 (Cold Spring Harbor Laboratory Press, 1998).

5. Valadkhan, S. snRNAs as the catalysts of pre-mRNA splicing. Curr. Opin. Chem. Biol. 9, 603-608 (2005).

6. Staley, J. P. \& Guthrie, C. Mechanical devices of the spliceosome: motors, clocks, springs, and things. Cell 92, 315-326 (1998).

7. Liu, Y. C. \& Cheng, S. C. Functional roles of DExD/H-box RNA helicases in Pre-mRNA splicing. J. Biomed. Sci. 22, 54 (2015).

8. Semlow, D. R. \& Staley, J. P. Staying on message: ensuring fidelity in pre-mRNA splicing. Trends Biochem. Sci. 37, 263-273 (2012).

9. Cordin, O. \& Beggs, J. D. RNA helicases in splicing. RNA Biol. 10, 83-95 (2013)

10. Teigelkamp, S., Mundt, C., Achsel, T., Will, C. L. \& Lührmann, R. The human U5 snRNP-specific $100-\mathrm{kD}$ protein is an RS domain-containing, putative RNA helicase with significant homology to the yeast splicing factor Prp28p. RNA 3, 1313-1326 (1997).

11. Strauss, E. J. \& Guthrie, C. PRP28, a 'DEAD-box' protein, is required for the first step of mRNA splicing in vitro. Nucleic Acids Res. 22, 3187-3193 (1994).

12. Chang, T. H., Latus, L. J., Liu, Z. \& Abbott, J. M. Genetic interactions of conserved regions in the DEAD-box protein Prp28p. Nucleic Acids Res. 25, 5033-5040 (1997).

13. Jacewicz, A., Schwer, B., Smith, P. \& Shuman, S. Crystal structure, mutational analysis and RNA-dependent ATPase activity of the yeast DEAD-box pre-mRNA splicing factor Prp28. Nucleic Acids Res. 42, 12885-12898 (2014).

14. Laggerbauer, B., Achsel, T. \& Lührmann, R. The human U5-200kD DEXH-box protein unwinds U4/U6 RNA duplices in vitro. Proc. Natl Acad. Sci. USA 95, 4188-4192 (1998).

15. Yang, F. et al. Splicing proofreading at 5' splice sites by ATPase Prp28p. Nucleic Acids Res. 41, 4660-4670 (2013).

16. Möhlmann, S. et al. Structural and functional analysis of the human spliceosomal DEAD-box helicase Prp28. Acta Crystallogr. D Biol. Crystallogr. 70, 1622-1630 (2014).

17. Staley, J. P. \& Guthrie, C. An RNA switch at the 5 ' splice site requires ATP and the DEAD box protein Prp28p. Mol. Cell 3, 55-64 (1999). 
18. Chen, J. Y. et al. Specific alterations of U1-C protein or U1 small nuclear RNA can eliminate the requirement of Prp28p, an essential DEAD box splicing factor. Mol. Cell 7, 227-232 (2001).

19. Hage, R. et al. A targeted bypass screen identifies Ynl187p, Prp42p, Snu71p, and Cbp80p for stable U1 snRNP/Pre-mRNA interaction. Mol. Cell Biol. 29, 3941-3952 (2009).

20. Mathew, R. et al. Phosphorylation of human PRP28 by SRPK2 is required for integration of the U4/U6-U5 tri-snRNP into the spliceosome. Nat. Struct. Mol. Biol. 15, 435-443 (2008).

21. Roscigno, R. F. \& Garcia-Blanco, M. A. SR proteins escort the U4/U6.U5 tri-snRNP to the spliceosome. RNA 1, 692-706 (1995).

22. Makarova, O. V., Makarov, E. M. \& Lührmann, R. The 65 and $110 \mathrm{kDa}$ SR-related proteins of the U4/U6.U5 tri-snRNP are essential for the assembly of mature spliceosomes. EMBO J. 20, 2553-2563 (2001).

23. Meister, G. et al. SMNrp is an essential pre-mRNA splicing factor required for the formation of the mature spliceosome. EMBO J. 20, 2304-2314 (2001).

24. Rappsilber, J., Ajuh, P., Lamond, A. I. \& Mann, M. SPF30 is an essential human splicing factor required for assembly of the U4/U5/U6 tri-small nuclear ribonucleoprotein into the spliceosome. J. Biol. Chem. 276, 31142-31150 (2001).

25. Bessonov, S. et al. Characterization of purified human Bact spliceosomal complexes reveals compositional and morphological changes during spliceosome activation and first step catalysis. RNA 16, 2384-2403 (2010).

26. Agafonov, D. E. et al. Semiquantitative proteomic analysis of the human spliceosome via a novel two-dimensional gel electrophoresis method. Mol. Cell Biol. 31, 2667-2682 (2011).

27. Schneider, M. et al. Exon definition complexes contain the tri-snRNP and can be directly converted into B-like precatalytic splicing complexes. Mol. Cell 38, 223-235 (2010).

28. Wyatt, J. R., Sontheimer, E. J. \& Steitz, J. A. Site-specific cross-linking of mammalian U5 snRNP to the 5' splice site before the first step of pre-mRNA splicing. Genes Dev. 6, 2542-2553 (1992).

29. Sontheimer, E. J. \& Steitz, J. A. The U5 and U6 small nuclear RNAs as active site components of the spliceosome. Science 262, 1989-1996 (1993).

30. Reyes, J. L., Kois, P., Konforti, B. B. \& Konarska, M. M. The canonical GU dinucleotide at the 5 ' splice site is recognized by p220 of the U5 snRNP within the spliceosome. RNA 2, 213-225 (1996).

31. Ismaili, N., Sha, M., Gustafson, E. H. \& Konarska, M. M. The 100-kda U5 snRNP protein (hPrp28p) contacts the 5' splice site through its ATPase site. RNA 7, 182-193 (2001).

32. Cordin, O., Banroques, J., Tanner, N. K. \& Linder, P. The DEAD-box protein family of RNA helicases. Gene 367, 17-37 (2006).

33. Linder, P. \& Jankowsky, E. From unwinding to clamping - the DEAD box RNA helicase family. Nat. Rev. Mol. Cell Biol. 12, 505-516 (2011).

34. Price, A. M., Gornemann, J., Guthrie, C. \& Brow, D. A. An unanticipated early function of DEAD-box ATPase Prp28 during commitment to splicing is modulated by U5 snRNP protein Prp8. RNA 20, 46-60 (2014).

35. Schneider, M. et al. Human PRP4 kinase is required for stable tri-snRNP association during spliceosomal B complex formation. Nat. Struct. Mol. Biol. 17, 216-221 (2010).

36. Anokhina, M. et al. RNA structure analysis of human spliceosomes reveals a compact $3 \mathrm{D}$ arrangement of snRNAs at the catalytic core. EMBO J. 32, 2804-2818 (2013)

37. Behzadnia, N. et al. Composition and three-dimensional EM structure of double affinity-purified, human prespliceosomal A complexes. $E M B O$ J. 26, 1737-1748 (2007).

38. Boesler, C. et al. Stable tri-snRNP integration is accompanied by a major structural rearrangement of the spliceosome that is dependent on Prp8 interaction with the 5' splice site. RNA 21, 1993-2005 (2015).

39. Wolf, E. et al. Exon, intron and splice site locations in the spliceosomal B complex. EMBO J. 28, 2283-2292 (2009).

40. Rigo, N., Sun, C., Fabrizio, P., Kastner, B. \& Lührmann, R. Protein localisation by electron microscopy reveals the architecture of the yeast spliceosomal B complex. EMBO J. 34, 3059-3073 (2015).

41. Brow, D. A. \& Guthrie, C. Spliceosomal RNA U6 is remarkably conserved from yeast to mammals. Nature 334, 213-218 (1988).
42. Kuhn, A. N., Reichl, E. M. \& Brow, D. A. Distinct domains of splicing factor Prp8 mediate different aspects of spliceosome activation. Proc. Natl Acad. Sci. USA 99, 9145-9149 (2002).

43. Dignam, J. D., Lebovitz, R. M. \& Roeder, R. G. Accurate transcription initiation by RNA polymerase II in a soluble extract from isolated mammalian nuclei. Nucleic Acids Res. 11, 1475-1489 (1983).

44. Das, R. \& Reed, R. Resolution of the mammalian E complex and the ATP-dependent spliceosomal complexes on native agarose mini-gels. RNA 5, 1504-1508 (1999).

45. Hartmuth, K. et al. Protein composition of human prespliceosomes isolated by a tobramycin affinity-selection method. Proc. Natl Acad. Sci. USA 99, 16719-16724 (2002).

46. Kastner, B. et al. GraFix: sample preparation for single-particle electron cryomicroscopy. Nat. Methods 5, 53-55 (2008).

47. Golas, M. M., Sander, B., Will, C. L., Lührmann, R. \& Stark, H. Molecular architecture of the multiprotein splicing factor SF3b. Science 300, 980-984 (2003).

48. van Heel, M., Harauz, G., Orlova, E. V., Schmidt, R. \& Schatz, M. A new generation of the IMAGIC image processing system. J. Struct. Biol. 116, 17-24 (1996).

49. van Heel, M. Multivariate statistical classification of noisy images (randomly oriented biological macromolecules). Ultramicroscopy 13, 165-183 (1984).

50. Dube, P., Tavares, P., Lurz, R. \& van Heel, M. The portal protein of bacteriophage SPP1: a DNA pump with 13-fold symmetry. EMBO J. 12, 1303-1309 (1993).

51. Fabrizio, P., Laggerbauer, B., Lauber, J., Lane, W. S. \& Lührmann, R. An evolutionarily conserved U5 snRNP-specific protein is a GTP-binding factor closely related to the ribosomal translocase EF-2. EMBO J. 16, 4092-4106 (1997).

52. Boehringer, D. et al. Three-dimensional structure of a pre-catalytic human spliceosomal complex B. Nat. Struct. Mol. Biol. 11, 463-468 (2004)

\section{Acknowledgements}

We are grateful to G. Heyne, H. Kohansal, M. Raabe and U. Plessmann for technical assistance. We thank T. Conrad for the cultivation of HeLa cells. This work is supported by a grant (LU 294/15-1) from the Deutsche Forschungsgemeinschaft (DFG) to R.L. and by a grant from the Deutsche Forschungsgemeinschaft (SFB860, TP A02) to R.F.

\section{Author contributions}

All authors analysed the data and interpreted the results. C.B., N.R., M.A., M.T., C.W. and D.A. performed experiments. C.B., C.W. and R.L. wrote the manuscript. B.K., H.U., R.F., C.W. and R.L. supervised the project.

\section{Additional information}

Supplementary Information accompanies this paper at http://www.nature.com/ naturecommunications

Competing financial interests: The authors declare no competing financial interests.

Reprints and permission information is available online at http://npg.nature.com/ reprintsandpermissions/

How to cite this article: Boesler, C. et al. A spliceosome intermediate with loosely associated tri-snRNP accumulates in the absence of Prp28 ATPase activity. Nat. Commun. 7:11997 doi: 10.1038/ncomms11997 (2016)

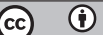

This work is licensed under a Creative Commons Attribution 4.0 International License. The images or other third party material in this article are included in the article's Creative Commons license, unless indicated otherwise in the credit line; if the material is not included under the Creative Commons license, users will need to obtain permission from the license holder to reproduce the material. To view a copy of this license, visit http://creativecommons.org/licenses/by/4.0/ 